\title{
LA ELECCIÓN IMPLÍCITA DE LA LEY APLICABLE A LA CLÁUSULA DE ARBITRAJE EN EL COMMON LAW
}

\author{
THE IMPLIED CHOICE OF THE PROPER LAW OF THE \\ ARBITRATION AGREEMENT UNDER THE COMMON LAW
}

\author{
JAVIER PÉREZ Font \\ Abogado \\ LLM (Distinction) in International Commercial and Maritime Law (Swansea University). \\ Doctorando en Derecho Internacional Privado en la Universidad Pública de Navarra \\ ORCID ID: 0000-0002-1554-5420
}

Recibido: 07.10.2020 / Aceptado: 03.11.2020
DOI: https://doi.org/10.20318/cdt.2021.5969

Resumen: A la hora de determinar la ley aplicable al convenio de arbitraje, el common law prevé que, a falta de elección expresa, se aplicará la ley implícitamente elegida. Con relación a las cláusulas de arbitraje, en el caso Sul América la Corte de Apelación de Inglaterra y Gales estableció la presunción de que la ley expresamente elegida como ley aplicable al contrato se entendería implícitamente elegida como ley aplicable a la cláusula de arbitraje. Recientemente, en el caso Enka la misma Corte de Apelación ha enmendado esta presunción, disponiendo que independientemente de la ley elegida para el contrato, la elección expresa de sede implicará la elección implícita de su ley como ley aplicable a la cláusula de arbitraje.

Palabras clave: common law, elección implícita, ley aplicable al convenio de arbitraje, ley de la sede, ley aplicable al contrato

\begin{abstract}
In order to identify the proper law of the arbitration agreement, common law provides that, in the absence of an express choice, it must be applied the law impliedly chosen by the parties. In relation to arbitration clauses contained in contracts, the Court of Appeal established in the Sul América case the presumption that the law expressly chosen to govern the contract is prima facie considered the impliedly chosen to govern the arbitration clause. Recently, amending this doctrine, in the Enka case the same Court of Appeal has estimated that the express designation of a seat prima facie amounts to the implied choice of its law as the proper law of the arbitration clause.
\end{abstract}

Keywords: common law, implied choice, proper law of the arbitration agreement, law of the seat, law governing the contract.

Sumario: I. Introducción. II. La ley de la sede como ley con la conexión más estrecha y real: $C$ v $D$ [2007] EWCA Civ 1282. III. La elección expresa de ley aplicable al contrato como elección implícita de ley aplicable a la cláusula de arbitraje: 1. Sul América Cia Nacional de Seguros SA \& Others $v$ Enesa Egenharia SA \& Others [2012] 1 Lloyd's Rep 671: A) Hechos y fallo en primera instancia; B) El fallo de la Corte de Apelación; C) Consecuencias del fallo en la determinación de la ley aplicable al convenio de arbitraje; D) Análisis crítico; 2. Arsanovia Ltd \& Others v Cruz City 1 Mauritius Holdings [2013] 1 Lloyd's Rep 235; 3. BNA v BNB \& BNC [2019] SGCA 84. IV. La elección de la sede como elección implícita de ley aplicable a la cláusula de arbitraje: Enka Insaat Ve Sanayi $A S$ $v$ OOO Insurance Company Chubb \& Others [2020] EWCA Civ 574: 1. Hechos; 2. Fallo de la Corte de Apelación; 3. Fallo del Tribunal Supremo del Reino Unido; 4. Análisis crítico. V. Conclusiones.

\footnotetext{
*"The project leading to these results has received funding from UNED Pamplona, Caja Navarra Foundation and "la Caixa" Foundation, under agreement LCF/PR/PR15/51100007".
} 


\section{Introducción}

1. De la panoplia de leyes que pueden entrar en juego en un arbitraje internacional ${ }^{1}$, la ley aplicable al convenio de arbitraje - a la que denominaremos lex arbitri, aunque en ocasiones esta denominación se utiliza también para referirse a la ley aplicable al procedimiento- es una de las más relevantes al encargase de regular aspectos tan trascendentales como la validez del convenio ${ }^{2}$ o su alcance personal y material ${ }^{3}$.

2. Siendo incuestionable que una de las proyecciones del principio de autonomía de la voluntad en relación al convenio de arbitraje es la facultad de las partes de elegir qué ley debe operar como lex arbitri, esta elección sería conveniente que se realizará de manera expresa en el propio convenio; sin embargo, resulta habitual que las partes se limiten a configurar aspectos básicos como la sede o el tipo de arbitraje, pero no concreten qué ley resulta aplicable al convenio ${ }^{4}$, debiéndose ésta identificar en fase arbitral o judicial.

3. No resultando aplicable a la cuestión el Reglamento Roma $\mathrm{I}^{5}$, haciendo uso de la norma de conflicto aplicable para la determinación de la ley aplicable a los contratos ${ }^{6}$, en las jurisdicciones com-

\footnotetext{
${ }^{1}$ Como es bien sabido, una de las principales características del arbitraje internacional es la potencial presencia de múltiples ordenamientos jurídicos. Junto a la ley aplicable al convenio de arbitraje, generalmente encontraremos otras dos normas que serán fundamentales: (a) la ley aplicable al procedimiento, que generalmente será la ley del lugar de la sede del arbitraje; (b) la ley aplicable al fondo del asunto o lex causae, que en el caso de disputas contractuales coincidirá con la lex contractus. Junto a estos sistemas normativos, entre otros, también podría adquirir relevancia la ley personal de las partes - por ejemplo, el artículo V(1)(a) del Convenio de Nueva York de 1958 estipula la falta de capacidad de las partes conforme a su ley personal como motivo para denegar el reconocimiento y ejecución del laudo por no ser válido el convenio de arbitraje - o la ley del lugar dónde se busque el reconocimiento y ejecución del laudo - por ejemplo, el artículo V(2)(a) contempla la posibilidad de denegación del reconocimiento y ejecución de un laudo por tratar sobre materias no arbitrales conforme a la ley del Estado en que se busque el reconocimiento y ejecución -. Ver: D. Sutton, J. Gill \& M. Gearing, Russell on Arbitration (24th edn, Sweet \& Maxwell 2015) paras 2-113; A. REDFERn, Redfern \& Hunter: Law and Practice of International Commercial Arbitration (6th edn, Sweet \& Maxwell 2015) párrafo 3.07.

${ }^{2}$ Con relación a la validez existen dos posiciones doctrinales diferenciadas. Mientras una corriente sostiene que será la ley aplicable al convenio la que regule tanto la validez formal como material del convenio - ver: J. HiLL \& A. ChONG, International Commercial Disputes: Commercial Conflict of Laws in English Courts (4th edn, Hart Publishing 2010) párrafo 21.1.5; R.M MERKIN \& L. FLANNERY, Arbitration Act 1996 (4th edn, Informa Law 2008) p. 207-208-, otra considera que es necesario distinguir entre la validez material y la formal, estando la primera regulada por la lex arbitri y la segunda por la ley aplicable al arbitraje que será generalmente la lex locus arbitri - "Among the questions dealt with by mandatory provisions of the [law applicable to the arbitration] we would mention foremost the form of the arbitration agreement (...) [this law does] not generally deal with the following questions, which therefore fall under the law applicable to the arbitration agreement: the material validity of the agreement, notably the prerequisites of its conclusion, defects in contract formation, and grounds for termination, interpretation (...)" [J.F. Poudret \& S. Besson, Comparative Law of International Arbitration (2nd edn, Sweet \& Maxwell 2007) p. 294-295] -. En mi opinión es preferible la primera opción por dos motivos intrínsecamente relacionados: en primer lugar, el sometimiento de ambas vertientes de la validez a un único cuerpo legislativo simplifica la supervisión de la validez del acuerdo de arbitraje; y, en segundo lugar, no siempre es nítida la distinción entre cuestiones formales y materiales, por lo que el sometimiento a un único ordenamiento legislativo reduce el riesgo de ineficacia del convenio que pudiera derivarse de que una cuestión fuera considerada formal y válida para un ordenamiento jurídico y, en cambio, para otro fuera material e inválida. No obstante, en la mayoría de los casos no tendrá especial relevancia ya que, como veremos, la ley aplicable al convenio de arbitraje generalmente será la ley del lugar de la sede que, a su vez, habitualmente será también la ley aplicable al arbitraje. Además, tanto la popularidad de la Ley Modelo, como el hecho de que la validez formal se aborde específicamente por los artículo II(1) y (2) de la Convención de Nueva York de 1958, han venido a diluir significativamente la relevancia de la validez formal del convenio. Ver: CGJ MoRSE, D. McClean \& L.A Collins, Dicey, Morris \& Collins on Conflict of Laws (15th edn, Sweet \& Maxwell 2018) párrafo 16-023.

${ }^{3}$ J.F. Poudret \& S. Besson, Comparative Law of... op. cit. p. 295; CGJ Morse, D. McClean \& L.A Collins, Dicey, Morris \& Collins... op. cit. párrafo 16-022.

${ }^{4}$ Como comentaba el High Court de Singapur en el primer párrafo de su sentencia en el caso FirstLink Investments Corp Ltd v GT Payment Pte Ltd \& Others [2014] SGHCR 12: "It is not uncommon that commercial parties omit to include in their contracts an express choice of law governing their international arbitration agreements". En similar sentido, ver: R. NAzZINI, The law applicable to the arbitration agreement: towards transnational principles (2016) 65 International \& Comparative Law Quaterly 681, p. 681-682.

${ }^{5}$ El artículo 1(2)(e) del Reglamento 593/2008 del Parlamento Europeo y del Consejo, de 17 de junio de 2008, sobre la ley aplicable a las obligaciones contractuales (Roma I).

${ }^{6}$ R. NAZZINI, The law applicable... op. cit. p. 687.
} 
mon law los operadores aplicarán al convenio de arbitraje la ley expresa o implícitamente elegida por las partes y, faltando esta elección, la ley que presente una conexión más estrecha y real con el arbitraje, siendo generalmente ésta la ley del lugar de la sede - la que denominaremos lex locus arbitri ${ }^{-}$.

4. Siendo la identificación de la elección implícita la más problemática, los tribunales han establecido una serie de presunciones que, dependiendo en gran medida de la forma que revista el convenio de arbitraje, sirven de guía para identificar prima facie qué ley deberá entenderse implícitamente elegida como lex arbitri por las partes de un convenio de arbitraje que carece de elección expresa.

5. Como si se tratara de un asunto circular que cada década hubiera de modificarse para volver a lo inmediatamente anterior, el pasado 20 de Abril la Corte de Apelación de Inglaterra y Galés en el caso Enka Insaat Ve Sanayi AS v OOO Insurance Company Chubb \& Others ${ }^{8}$ vino a modificar la doctrina previamente fijada por la misma Corte en el famoso caso Sul América Cia Nacional de Seguros $S A \&$ Others $v$ Enesa Egenharia SA \& Others $^{9}$. A diferencia de lo ocurrido en las ocasiones anteriores, no ha habido que esperar una década para ver otro cambio, sino tan sólo 6 meses. En una votación muy ajustada, siguiendo en gran medida el razonamiento adoptado por la Corte de Apelación en el caso Sul América, el 9 de Octubre el Tribunal Supremo del Reino Unido ha enmendado la decisión del 20 de Abril de la Corte de Apelación fijando de una vez por todas el método a seguir para determinar la ley aplicable a una cláusula de arbitraje ${ }^{10}$.

6. Teniendo en cuenta la posición predominante de Londres como sede para el arbitraje de disputas comerciales internacionale ${ }^{11} \mathrm{y}$ de la influencia de su jurisprudencia en materia arbitral y muy especialmente en el resto de las jurisdicciones common law, el objetivo del presente artículo es analizar la evolución en la aplicación de la norma de conflicto en lo relativo a la identificación de la lex arbitri implícitamente elegida por las partes. Para ello, en base al examen de varios leading cases, el análisis se estructurará en cuatro partes: en primer lugar, se analizará los antecedentes del caso Sul América; después analizaremos el caso Sul América y algunos casos en que se ha aplicado; en tercer lugar, examinaremos el caso Enka y finalizaremos extrayendo algunas conclusiones.

\section{La ley de la sede como ley con la conexión más estrecha y real: $C v D$ [2007] EWCA Civ 1282}

7. $\mathrm{D}$ - una empresa aseguradora norteamericana - emitió una póliza a favor de $\mathrm{C}$ - otra empresa norteamericana - que tenía por objeto cubrir las posibles responsabilidades civiles en que pudiera incurrir la asegurada y sus más de 303 empresas subsidiarias durante el período comprendido entre el 1 de Noviembre de 1997 y el 1 de Noviembre de 2000. La póliza se celebró en un famoso modelo estandarizado de póliza ${ }^{12}$ cuya cláusula (o) contiene una cláusula de arbitraje en Londres conforme al derecho inglés $^{13}$, y la cláusula (q) contiene una elección expresa del derecho de Nueva York como lex contractus $^{14}$.

\footnotetext{
${ }^{7}$ CGJ Morse, D. McClean \& L.A Collins, Dicey, Morris \& Collins... op. cit. párrafo 16R-001; D. Sutton, J. Gill \& M. GEARING, Russell on Arbitration ... op. cit. párrafo 2-119.

${ }^{8}$ Enka Insaat Ve Sanayi AS v OOO Insurance Company Chubb \& Others [2020] EWCA Civ 574.

${ }^{9}$ Sul América Cia Nacional de Seguros SA \& Others v Enesa Egenharia SA \& Others [2012] 1 Lloyd's Rep 671.

${ }^{10}$ Enka Insaat Ve Sanayi AS v OOO Insurance Company Chubb \& Others [2020] UKSC 38.

${ }^{11}$ En un estudio realizado por la Universidad de Londres en el año 2018, los cinco principales foros del arbitraje comercial internacional son: Londres, Paris, Singapur, Hong Kong y Ginebra. De estos, Londres era la opción preferente, siendo marcado por el $68 \%$ de los encuestados como uno de lo foros habitualmente utilizados por sus empresas, aventajando en más en más de 10 punto al segundo, Paris. Ver: ‘2018 International Arbitration Survey: The Evolution of International Arbitration' Queen Mary University of London disponible en https://tinyurl.com/y3nyf4q8

${ }^{12}$ El famoso Bermuda Form.

${ }^{13}$ La cláusula (o) reza así: "Any dispute arising under this Policy shall be finally and fully determined in London, England under the provisions of the English Arbitration Act of 1950 as amended (...)".

${ }^{14}$ La cláusula (q) dice así: "This policy shall be governed by and construed in accordance with the internal laws of the State of New York (...)".
} 
8. Durante el período de vigencia de la póliza, especialmente como consecuencia de actuaciones de una subsidiaria, $\mathrm{C}$ tuvo que hacer frente a varias reclamaciones que desembocaron en una subsiguiente repetición de conformidad con la póliza contra $\mathrm{D}$ por los importes abonados. Ésta se negó a responder de dichas cantidades lo que llevo a $\mathrm{C}$ a reclamarlas en sede arbitral.

$\mathrm{D}$ respondió a la demanda de $\mathrm{C}$ planteando frente al órgano arbitral cuatro defensas. A la vista de ellas, los árbitros notificaron el 20 de Febrero del 2007 que resolverían en primer término las 3 primeras y, únicamente si éstas eran desestimadas, analizarían la cuarta. El 13 de marzo del 2007, el tribunal adoptó un laudo parcial en que desestimaba íntegramente las 3 defensas planteadas por D y estimaba íntegramente las peticiones de C. Asimismo, el laudo establecía que únicamente consideraría la cuarta defensa si concurrían unas circunstancias determinadas.

Considerando que los árbitros habían conculcado manifiestamente el derecho de Nueva York, la aseguradora solicitó a los árbitros que enmendara el laudo parcial. Los árbitros le contestaron que, siendo una decisión firme, carecían de jurisdicción para llevar a cabo tal cosa y simplemente se limitaron a corregir algunos errores formales de menor importancia.

A la vista de su fracaso en vía arbitral, D decidió impugnar el laudo ante los tribunales de Nueva York. Considerando que esto suponía un incumplimiento manifiesto del acuerdo de arbitraje, C solicitó entonces a las autoridades judiciales inglesas la adopción de unas anti-suit injunctions ${ }^{15}$ que instaran a la aseguradora a renunciar al procedimiento judicial iniciado en Norteamérica. C argumentaba que, tratándose de un arbitraje en Londres conforme a la Ley Inglesa de Arbitraje, el único foro competente para conocer de la impugnación del laudo era Inglaterra. Por su parte, D argumentaba que existía una elección expresa de Nueva York como lex contractus y que en dicha ley existe un derecho indisponible de las partes de un acuerdo de arbitraje a someter a la revisión de sus tribunales aquellos laudos adoptados en el extranjero en relación con disputas entre empresas norteamericanas. La aseguradora argumentaba que la elección del derecho inglés como derecho aplicable al procedimiento no podía privarle de un derecho reconocido en un ordenamiento jurídico expresamente elegido por las partes para regir la integridad del contrato, incluida la cláusula de arbitraje.

9. En primera instancia ${ }^{16}$, Cooke $\mathrm{J}$ consideró que, siendo cierto que la aseguradora pudiera tener razón en lo referente a la inobservancia del derecho de Nueva York, no lo tenía en lo referente a la influencia que su elección pudiera tener en el arbitraje. Su Señoría argumentó que la elección de Londres como sede y el reconocimiento expreso en la póliza de que las decisiones arbitrales únicamente podrían ser impugnadas de conformidad con lo previsto en la Ley Inglesa de Arbitraje conllevaban que, independientemente de lo que pudiera prever el derecho de Nueva York, el planteamiento de una impugnación del laudo ante unos tribunales que no fueran los ingleses conllevaba un incumplimiento del acuerdo de arbitraje. Asimismo, negó que la elección expresa del derecho de Nueva York como lex contractus conllevara que fuera también la normativa que debiera operar como lex arbitri. En su opinión, la elección de la sede

\footnotetext{
${ }^{15}$ Las anti-suit injuctions son unas órdenes judiciales que, dirigidas contra una persona, tienen por objeto que su renuncia a continuar o a comenzar un procedimiento judicial al que no se tiene derecho ante unos tribunales extranjeros, generalmente por estar incumpliendo un acuerdo de arbitraje o de sumisión - "[Anti-suit injunctions are orders addressed to the person over whom Courts have] jurisdiction from continuing with or commencing proceedings in a foreign court if is inequitable for such person so to act" [Halsbury's Laws of England, 524] -. Este tipo de medidas surgieron para solventar los conflictos entre los dos sistemas jurídicos y judiciales paralelos existentes en la Inglaterra del siglo XV: los Courts of Equity y los Courts of Common law [A.L. Calvo Caravaca, J. Carrascosa González \& C. CaAmiña Dominguez, Litigación Internacional En La Unión Europea. I, Competencia Judicial y Validez de Resoluciones En Materia Civil y Mercantil En La Unión Europea: Comentario al Reglamento Bruselas I Bis (1a edn, Aranzadi 2017) párrafo 144; C. OJIEgBe, From West Tankers to Gazprom: Anti-Suit Injunctions, Arbitral Anti-Suit Orders and the Brussels I Recast (2015) 11 Journal of Private International Law 267, 271]. En relación a los convenios de arbitraje, su adopción se realizará al amparo de la sección 37 del Senior Courts Act 1981 (UstKamenogorsk Hydropower Plant JSC v AES Ust-Kamenogorsk Hydropower Plant LLP [2013] UKSC 35 [48]) y se requerirá para ello el cumplimiento de los siguientes requisitos: (a) El acuerdo de arbitraje habrá de ser válido; (b) La acción planteada ante los tribunales extranjeros debe realizarse por una parte del convenio de arbitraje y en relación a una cuestión que entre dentro del ámbito del convenio; (c) No debe haber transcurrido demasiado tiempo desde que se hubiera planteado la acción ante los tribunales extranjeros; (d) No debe haberse producido la sumisión tácita del solicitante a la jurisdicción de los tribunales extranjeros; y (e) debe entenderse conveniente su adopción por parte del tribunal requerido.

${ }^{16} C v D$ [2007] 2 Lloyd's Rep 367.
} 
en Londres y del derecho inglés como ley aplicable al procedimiento indicaban que la ley aplicable a la cláusula de arbitraje era la inglesa. Por tanto, estimó la petición de adopción de las anti-suit injunctions.

10. Frente a esta decisión se planteó entonces recurso ante la Corte de Apelación. La principal alegación del apelante era que Cooke $\mathrm{J}$ había errado al determinar que, por el hecho de elegir Londres como sede, era la ley inglesa la que debía aplicarse a la cláusula de arbitraje. La aseguradora argumentaba que, ante el silencio de la cláusula, debía considerarse que la ley expresamente elegida para regir el contrato debía aplicarse a todas las cláusulas del contrato, incluida la cláusula de arbitraje. De estimarse esta alegación, argumentaba que deberían dejarse sin efecto las anti-suit injunctions adoptadas porque no se podría impedir ejercitar una acción de impugnación permitida por la ley aplicable al acuerdo de arbitraje. Por su parte, el apelado alegaba que toda la argumentación del apelante era irrelevante porque desde el momento en que se había elegido a Londres como sede y al derecho inglés como ley aplicable al procedimiento, las partes habían admitido que las únicas impugnaciones posibles a las decisiones arbitrales serían las admitidas por el derecho inglés, con independencia de lo que pudieran disponer la lex contractus o la lex arbitri, si es que ambas no eran la misma.

11. En un fallo al que posteriormente se referirán los leading cases que veremos a continuación, la Corte de Apelación rechaza la argumentación del apelante. En primer lugar, Longmore LJ - el ponente con el que estarán de acuerdo sus compañeros - manifiesta que la elección de la sede en Londres y del derecho inglés como ley aplicable al procedimiento significa que las decisiones arbitrales únicamente se podrán someter a los medios de impugnación previstos en el derecho inglés ${ }^{17}$. Además, rechaza que la mera elección del derecho aplicable al contrato pueda suponer la incorporación al arbitraje de un método de impugnación no previsto en el ordenamiento jurídico inglés ${ }^{18}$, ni la exclusión de aquellas disposiciones del derecho inglés que, siendo dispositivas, impedirían a la aseguradora plantear una impugnación del laudo ante los tribunales de Nueva York ${ }^{19}$.

12. En segundo lugar, la Corte de Apelación entra a analizar la cuestión de la identificación de la ley aplicable al acuerdo de arbitraje. Como consecuencia de lo decidido en el primer punto la apelación ya debía ser desestimada; sin embargo, Longmore LJ considera que, habiéndose debatido en sala, debía manifestar su opinión al respecto ${ }^{20}$.

Analizando las autoridades existentes en la materia, la Corte de Apelación considera que, a partir del reconocimiento del principio de separabilidad ${ }^{21}$, la cláusula de arbitraje representa funcionalmente un acuerdo independiente del contrato en que se inserta ${ }^{22}$. Esto supone que, de la misma manera

\footnotetext{
${ }^{17} C v D$ [2007] EWCA Civ 1282 [16-17].

18 ibidem [19].

${ }^{19}$ En este punto, siguiendo la opinión de Lord Steyn en Lesotho Highland Development Authority v Impregilo SpA \& Others [2006] 1 AC 221 [37] y la redacción del artículo 4(5) de la Ley de Arbitraje de 1996 - "The choice of a law other than the law of England and Wales or Northern Ireland as the applicable law in respect of a matter provided for by a non-mandatory provision of this Part is equivalent to an agreement making provision about that matter" -, la Corte de Apelación concluye que para que se produzca una exclusión de un precepto dispositivo de la Ley Inglesa de Arbitraje como consecuencia de la elección de una norma jurídica extranjera, no bastará con una elección genérica, sino que será necesario que le elección prevea que disposiciones específicas pretende excluir - "Lord Steyn (...) pointed out (...) that by reason of section 5 of the Act only an agreement in writing as defined by the 1996 Act could qualify as an "agreement to the contrary" and that a choice of proper law clause was not such an agreement. That is reinforced by the terms of section 4(5) of the Act which refers not to a choice of law clause generally but to a choice of law as "the applicable law in respect of a matter provided for by a non-mandatory provision of this part" of the Act. In other words there has to be a choice of law with regard to the specific provision of the Act which the parties agree is not to apply" (énfasis añadido) (CvD [2007] EWCA Civ 1282 [19]) -

${ }^{20} C v D$ [2007] EWCA Civ 1282 [21].

${ }^{21}$ Antes de su positivización en el actual artículo 7 de Ley de Arbitraje de 1996, los tribunales ingleses habían reconocido ya de manera rotunda el principio de separabilidad en el famoso caso Harbour Assurance Co (UK) Ltd v Kansa General International Insurance Co Ltd [1993] 1 Lloyd's Rep 455. El camino hacia el reconocimiento del principio de separabilidad comenzó en 1942 cuando la Cámara de los Lores en el caso Heyman v Darwins Ltd [1942] AC 356 rechazó obiter dictae que una cláusula de arbitraje tuviera que sufrir los designios del contrato en que se inserta no siendo capaz de sobrevivir independientemente.

${ }^{22} C v D$ [2007] EWCA Civ 1282 [22].
} 
que para determinar la lex contractus se debe atender a la conexión más estrecha y real del contrato con independencia de lo que pueda prever una cláusula de arbitraje en él inserta ${ }^{23}$, la lex arbitri se habrá de determinar atendiendo a la conexión más estrecha y real del convenio de arbitraje con independencia de lo que prevea el contrato en que se inserta ${ }^{24}$.

Partiendo de esa premisa y considerando las opiniones de Lord Mustill en Black Clawson International Ltd $v$ Papierwerke Waldhof-Aschaffenburg $A G^{25} \mathrm{y}$ en Channel Tunnel Group Ltd $v$ Balfour Beatty Construction $L_{t d}{ }^{26}$, Longmore LJ estima que, dada su estrecha vinculación, resultaría extraño que las partes optaran por someter el acuerdo de arbitraje a una ley diferente de la del lugar elegido como sede. Por ello, independientemente de que la ley de Nueva York fuese expresamente elegida como lex contractus, la Corte de Apelación concluye que la ley aplicable a la cláusula arbitral ha de ser la ley inglesa porque es la ley que presenta una conexión más estrecha y real con el arbitraje ${ }^{27}$.

13. En consecuencia, la Corte de Apelación dispone que, existiendo una elección expresa de lex contractus y de sede del arbitraje, la ley aplicable a la cláusula de arbitraje será la lex locus arbitri.

\section{La elección expresa de ley aplicable al contrato como elección implícita de ley aplicable a la cláusula de arbitraje}

\section{Sul América Cia Nacional de Seguros SA \& Others v Enesa Egenharia SA \& Others [2012] 1 Lloyd's Rep 671}

\section{A) Hechos y fallo en primera instancia}

14. El demandante - una empresa aseguradora - emitió dos pólizas con similar contenido a favor del demandado con el objetivo de cubrir los riesgos que pudieran ocasionarse durante la construcción en Brasil de una de las plantas hidroeléctricas más grandes del mundo. Mientras la cláusula número 7 de las

\footnotetext{
${ }^{23}$ En Tzortzis and Skyias v Monark Line A/B [1968] 1 Lloyd's Rep 30 - un caso concerniente a un contrato de compraventa de un buque de bandera sueca que, conteniendo una cláusula de arbitraje en Londres, no identificaba qué ley le era aplicable - se consideró que, de conformidad con la máxima latina de "Qui elegit iudicem elegit ius", la elección de Londres como sede del arbitraje debía asimismo entenderse como sumisión del contrato al derecho inglés. Esto siempre se había interpretado también a la inversa, es decir, que existiendo una elección expresa de ley aplicable al contrato, esa misma ley resultaría aplicable a la cláusula de arbitraje. Sin embargo, en Compagnie Tunisienne De Navegation SA v Compagnie D'Armement Maritime SA [1970] 2 Lloyd's Rep 99 - un caso concerniente a un contrato de fletamento por viaje que cubría un transporte de petróleo desde Túnez a Francia a pagar en Francia y que contenía tanto una cláusula de elección de lex contractus de contenido difuso como otra de arbitraje en Londres - , la Cámara de los Lores concluyó que las partes habían elegido expresamente la ley francesa como lex contractus, pero que aun no habiendo sido así, la determinación de la ley aplicable al contrato debía hacerse atendiendo a la conexión más estrecha y real, siendo evidente que, a pesar del arbitraje en Londres, la ley francesa presentaba una conexión más estrecha y real con el contrato.

${ }^{24} C v D$ [2007] EWCA Civ 1282 [23].

25 "In the great majority of cases, these three laws will be the same. But this will not always be so. It is by no means uncommon for the proper law of the substantive contract to be different from the [lex locus arbitri]; and it does happen, although much more rarely, that the law governing the arbitration agreement is also different from the [lex locus arbitri]" (Black Clawson International Ltd v Papierwerke Waldhof-Aschaffenburg AG [1981] 2 Lloyd's Rep 446453 ).

26 "It is by now firmly established that more than one national system of law may bear upon an international arbitration. Thus, there is the proper law which regulates the substantive rights and duties of the parties to the contract from which the dispute has arisen. Exceptionally, this may differ from the national law governing the interpretation of the agreement to submit the dispute to arbitration. Less exceptionally it may also differ from the national law which the parties have expressly or by implication selected to govern the relationship between themselves and the arbitrator in the conduct of the arbitration: the "curial law" of the arbitration, as it is often called. (...). Certainly there may sometimes be an express choice of a curial law which is not the law of the place where the arbitration is to be held: but in the absence of an explicit choice of this kind, or at least some very strong pointer in the agreement to show that such a choice was intended, the inference that the parties when contracting to arbitrate in a particular place consented to having the arbitral process governed by the law of that place is irresistible" (Channel Tunnel Group Ltd \& Others v Balfour Beatty Construction Ltd \& Others [1993] AC 334 357-358).

${ }^{27} C v D$ [2007] EWCA Civ 1282 [26].
} 
pólizas disponía que el derecho brasileño regiría el contrato ${ }^{28}$, la cláusula número 12 preveía que, en caso de disputa concernientes a la cuantía a abonar en caso de que sucediera un riesgo, ésta debía ser fijada mediante arbitraje en Londres ${ }^{29}$.

15. Como consecuencia de una serie de incidentes ocurridos en Marzo del 2011, el asegurado reclamó a la aseguradora una indemnización por daños y perjuicios a la que se opuso la aseguradora argumentando que los riesgos no estaban cubiertos por la póliza. En esta situación, con el objetivo de blindarse frente a cualquier acción posterior del asegurado, el 29 de Noviembre de 2011 la aseguradora instó el arbitraje en Londres con la intención de obtener un laudo declarativo que reconociera su falta de responsabilidad. En respuesta a la demanda de arbitraje, el asegurado buscó ante los tribunales brasileños una declaración de nulidad de la cláusula de arbitraje y obtuvo de manera cautelar de los tribunales de Sao Paulo una orden impidiendo a la aseguradora continuar con el arbitraje en Londres. Esto hizo que la aseguradora presentará entonces una solicitud ante los tribunales ingleses para obtener sin audiencia previa del demandado unas anti-suit injunctions contra el asegurado que fueron decretadas inicialmente por Stadlen J.

16. Oponiéndose a las anti-suit injunctions adoptadas, el asegurado argumentó que, al igual que el resto de las cláusulas del contrato, la cláusula de arbitraje se regía por el derecho brasileño y que conforme a éste el arbitraje únicamente podía instarse por él, no por la aseguradora. En contraposición la aseguradora argumentó que el derecho aplicable a la cláusula era el derecho inglés y que, por tanto, no había motivos para no mantener las medidas adoptadas porque el convenio de arbitraje era válido y al presentar una acción ante los tribunales brasileños el asegurado estaba incumpliendo el convenio de arbitraje. Por tanto, la cuestión principal a resolver era si la cláusula de arbitraje se regía por el derecho brasileño o por el inglés, de regirse por el primero las anti-suit injunctions debían dejarse sin efecto.

17. En primera instancia, Cooke $\mathrm{J}$ consideró que, a la hora de determinar la ley aplicable al acuerdo de arbitraje, a falta de una elección expresa, los tribunales debían buscar el ordenamiento jurídico que presentará una conexión más estrecha y real con el convenio de arbitraje. Siendo posible que en aquellos supuestos en que el convenio reviste la forma de una cláusula del contrato la lex arbitri sea diferente a la lex contractus, el mero hecho de que la cláusula de arbitraje estuviera inserta en un contrato sometido expresamente al derecho brasileño no conllevaba que éste fuera de por si el derecho aplicable al convenio de arbitraje. De hecho, siguiendo las autoridades previas ${ }^{30}$, su señoría concluyó que, teniendo en cuenta la trascendencia para el arbitraje que tiene la elección de Londres como sede, era la ley inglesa la que presentaba una conexión más estrecha y real y, por tanto, que debía ser ésta la que operase como lex arbitri ${ }^{31}$.

\section{B) El fallo de la Corte de Apelación}

18. Al conocer de la apelación a la decisión adoptada por Cooke J, la Corte de Apelación - compuesta por Neuberger MR, Moore-Bick LJ y Hallett LJ - se enfrenta en esencia a la misma cuestión a la que se enfrentó el tribunal de primera instancia: ¿cuál es el derecho aplicable a la cláusula de arbitraje: el derecho inglés o el derecho brasileño?

\footnotetext{
28 "It is agreed that this policy will be governed exclusively by the laws of Brazil" rezaba literalmente la cláusula número 7.

${ }^{29}$ La cláusula 12 específicamente decía: "In case the Insured and the Insurer(s) shall fail to agree as to the amount to be paid under this Policy through mediation as above, such dispute shall then be referred to arbitration under ARIAS Arbitration Rules (...) The seat of the arbitration shall be London, England".

${ }^{30}$ Además del caso $C v D$ examinado previamente, la Corte de Apelación tomó por referencia el caso Shashoua \& Others $v$ Sharma [2009] EWHC 957 (Comm). En este caso, un contrato sometido expresamente al derecho indio contenía una cláusula que preveía un arbitraje conforme a las reglas de la Cámara Internacional de Comercio con Londres como "venue of arbitration". La elección del derecho indio como lex contractus y la utilización del termino "venue" en vez del término "seat" dio lugar a un debate entre el demandante y el demandado acerca de si Londres era la sede o una mera localización dónde debían tener lugar las audiencias y sesiones. El Tribunal consideró que la mención "venue" sin el establecimiento de otro lugar geográfico alternativo inexorablemente conllevaba que Londres debía ser considerada la sede.

${ }^{31}$ Sul América Cia Nacional de Seguros SA \& Others v Enesa Egenharia SA \& Others [2012] 1 Lloyd's Rep 275 [11-15].
} 
19. Con su brillantez habitual, Moore-Bick LJ comienza reconociendo que es perfectamente posible que las partes opten por la cláusula de arbitraje a un ordenamiento jurídico diferente de aquél que rija el contrato en que aquélla se inserta. Sin embargo, a falta de un ejercicio expreso de esta disociación entre lex arbitri y lex contractus, Moore-Bick LJ considera que lo lógico es presumir que cuando las partes han elegido expresamente un ordenamiento jurídico para que rija el contrato, la elección se haga con respecto a todas las cláusulas del mismo, incluida el convenio de arbitraje ${ }^{32}$. En consecuencia, la Corte de Apelación establece la premisa de que existiendo una elección expresa de lex contractus y careciendo la cláusula arbitral de una elección expresa de lex arbitri, se entenderá prima facie que las partes han elegido implícitamente como lex arbitri la ley expresamente elegida como lex contractus ${ }^{33}$.

Teniendo en cuenta que mientras la cláusula 7 expresamente sometía las pólizas al derecho brasileño, la 12 no contenía una elección expresa de lex arbitri, la aplicación de la premisa antes analizada conllevaría apoyar la moción del apelante/asegurado y concluir que el derecho brasileño debía operar como ley aplicable a la cláusula de arbitraje. Sin embargo, en el caso concreto existen dos factores que conjuntamente valorados destruyen dicha presunción y llevan a concluir que las partes no han elegido implícitamente el derecho brasileño como lex arbitri: la elección de Londres como sede y el hecho de que, si la cláusula estuviera sometida al derecho brasileño, devendría ineficaz.

Respecto al primero de los dos factores, la elección de Londres como sede, el tribunal considera que teniendo en cuenta que dicha elección conlleva la localización jurídica del arbitraje en Inglaterra, podía entenderse que la intención de las partes era que fuera la ley inglesa la que regulara todos los aspectos relativos al arbitraje, incluyéndose cuestiones como la validez del acuerdo o la jurisdicción del órgano arbitral ${ }^{34}$.

En cuanto al segundo de los factores, habida cuenta de que si el derecho brasileño era el aplicable al convenio de arbitraje, éste sería ineficaz, Moore-Bick LJ concluye que no parecería propio de las partes de un convenio de arbitraje someterlo a un ordenamiento jurídico conforme al cual dicho convenio no resultaría operativo ${ }^{35}$.

20. No existiendo elección expresa y habiéndose descartado la existencia de una elección implícita del derecho brasileño, aplicando las normas de conflicto del common law, la ley que presente la conexión más estrecha y real con el arbitraje será la que resulta aplicable al convenio de arbitraje. Habiéndose elegido Londres como sede, es la ley inglesa la que presenta una conexión más estrecha y real con el arbitraje y, por tanto, será también la aplicable a las cláusulas de arbitraje previstas en las pólizas.

\section{C) Consecuencias del fallo en la determinación de la ley aplicable al convenio de arbitraje}

21. Separándose del criterio adoptado en el caso $C v D$ y por Cooke $\mathrm{J}$ en primera instancia, la Corte de Apelación establece una importante presunción aplicable a los de convenios de arbitraje que tomen la forma de una cláusula inserta en un contrato: la elección expresa de lex contractus se entenderá, salvo que concurran indicios que apunten en otro sentido, elección implícita de la ley aplicable a la cláusula de arbitraje.

22. La aplicación de esta presunción a la norma de conflicto del common law establecida para determinar la ley aplicable al convenio de arbitraje da como resultado lo siguiente:

1) No tratándose de una cláusula de arbitraje sino de un auténtico acuerdo de arbitraje:

a) Existiendo una elección expresa de lex arbitri, el tribunal se atendrá a dicha elección.

\footnotetext{
${ }^{32}$ Sul América Cia Nacional de Seguros SA \& Others v Enesa Egenharia SA \& Others [2012] 1 Lloyd’s Rep 671 [11].

${ }^{33}$ ibidem 26.

${ }^{34}$ ibidem 29.

${ }^{35}$ ibidem 30-31.
} 
b) No existiendo una elección expresa de lex arbitri, pero existiendo en cambio una elección de sede, se entenderá prima facie que las partes han elegido implícitamente la ley del lugar de la sede como ley aplicable al convenio de arbitraje.

c) Por último, no existiendo designación expresa o implícita de lex arbitri, habrá de atenderse a las circunstancias, siendo aplicable la ley que presente una conexión más estrecha y real con el caso.

2) Tratándose de una cláusula de arbitraje, la determinación de la lex arbitri seguirá los pasos que acabamos de observar, pero con algunas modificaciones derivada de su inserción en el seno de un contrato:

a) Previendo expresamente la cláusula de arbitraje su sometimiento a un determinado ordenamiento jurídico será éste el que opere como lex arbitri, independientemente de si rige también o no el contrato en que se inserta la cláusula.

b) No conteniéndose una designación expresa de lex arbitri y existiendo una elección expresa de lex contractus, salvo que existan indicaciones que apunten en sentido contrario, se entenderá que la ley expresamente elegida para regir el contrato es la implícitamente elegida para regir también la cláusula de arbitraje.

c) No existiendo una designación expresa de lex arbitri, ni de lex contractus, se entenderá que resulta aplicable a la cláusula de arbitraje la ley que presente una conexión más estrecha y real con el arbitraje, siendo generalmente ésta la ley del lugar elegido como sede ${ }^{36}$.

\section{D) Análisis crítico}

23. Resulta incuestionable que la doctrina del caso Sul América guarda una relación que se podría tildar de problemática con el principio de separabilidad. Muchas críticas realizadas en este sentido han erróneamente identificado separabilidad con aislamiento y, parafraseando al poeta John Doone ${ }^{37}$, "no clause is an island".

24. A la hora de analizar el fallo de la Corte de Apelación hay tener en cuenta que, lejos de sostener una separabilidad equiparable a un aislamiento de la cláusula de arbitraje, tanto la normativa inglesa ${ }^{38}$

${ }^{36}$ En Habas Sinai Ve Tibbi Gazlar Isthisal Endustri AS v VSC Steel Company Ltd [2013] EWHC 4071 (Comm), el contrato contenía una cláusula de arbitraje en Londres, pero carecía de elección expresa de lex contractus y de lex arbitri. El tribunal consideró que en estas circunstancias no existía elección expresa o implícita de ley aplicable a la cláusula de arbitraje, debiéndose ésta determinar mediante el criterio residual de la conexión más estrecha y real. Así, a pesar de que conforme a las normas de conflicto resultaba aplicable al contrato la ley turca, a la cláusula de arbitraje le resultaba aplicable la ley inglesa por ser Londres la sede del arbitraje. Esta sentencia viene a confirmar la opinión de MERKIN \& FLANNERY acerca de la interrelación entre el fallo adoptado por la Corte de Apelación en el caso Sul América y lo dicho en el caso $C v D$ : "If there is no express choice of law governing the matrix contract, the nomination of the seat of the arbitration is likely to have more relevance but may not be necessarily be determinative of the law applicable to the arbitration agreement" [R.M MERKIN \& L. FLANNERY, Arbitration Act $1996 \ldots$ op. cit. p.211]. Ver también: R. NAzzinI, The law applicable ... op. cit. p. 691; D. Sutton, J. Gill \& M. GEARING, Russell on Arbitration... op. cit. Párrafo 2-120.

37 "No man is an island entire of itself; every man is a piece of the continent, a part of the main; if a clod be washed away by the sea, Europe is the less, as well as if a promontory were, as well as any manner of thy friends or of thine own were; any man's death diminishes me, because I am involved in mankind. And therefore never send to know for whom the bell tolls; it tolls for thee" [John Donne, Devotion upon Emergent Occasions, Meditation XVII].

${ }^{38}$ Con relación al alcance del principio de separabilidad, el comité encargado de la redacción de la Ley de Arbitraje de 1996 afirmaba expresamente: "The doctrine of separability is confined to the effect of invalidity of the main contract on the arbitration agreement" (énfasis añadido) [Departmental Advisory Committee on Arbitration Law 1996, "Report on the Arbitration Bill' (1996) párrafo 44]. Un ejemplo clásico del alcance del principio de separabilidad así definido es Fiona Trust \& Holding Corporation and Other v Privalov and Others [2008] 1 Lloyd's Rep 254. En este caso, los propietarios de unos buques alegaban que ocho contratos de fletamento del modelo estandarizado Shelltime 4 suscritos con los apelados eran fruto de un soborno al director general de una empresa estatal rusa. Los contratos contenían tanto una elección expresa del derecho inglés como lex contractus, como también una cláusula de arbitraje en Londres. Al conocer del soborno, los propietarios instaron ante la justicia 
como la ley modelo ${ }^{39}$ han venido a defender una visión limitada del principio de separabilidad conforme a la cual éste desplegaría sus efectos únicamente en aquellos supuestos en que, existiendo circunstancias que afecten a la validez del contrato en que se inserta la cláusula de arbitraje, pudiera verse afectada la validez, eficacia u existencia de la cláusula de arbitraje ${ }^{40}$. Por tanto, en la medida en que no se pusiera en cuestión la validez del contrato principal, no debería producirse la separación de la cláusula de arbitraje e impedirse así una interpretación sistemática de la misma.

25. Derivado de esto surge una primera cuestión en torno a Sul América ya que, no existiendo dudas sobre la validez de las pólizas de seguro y, en consecuencia, separación de la cláusula de arbitraje respecto del resto del contrato, nada hubiera impedido al asegurado alegar que la elección expresa del derecho brasileño como lex contractus era también una elección expresa de lex arbitri. Al no haberse realizado dicha alegación, nunca sabremos cuál hubiera sido la respuesta de la Corte de Apelación, pero su estimación hubiera cerrado el paso al análisis de la elección implícita y de la conexión más estrecha y real ${ }^{41}$.

26. Una segunda cuestión, es el rol proactivo que el intérprete asume cuando, no existiendo dudas sobre la validez del contrato en que se inserta la cláusula, al ver que su interpretación sistemática conduce a que las partes han elegido implícitamente una ley conforme a la cual el convenio de arbitraje es nulo, ineficaz o inoperativo, descarta dicha elección implícita y procede a determinar la lex arbitri conforme al criterio residual de la conexión más estrecha y real con el arbitraje, lo que de facto supone la separación de la cláusula de arbitraje respecto del resto de cláusulas del contrato en que se contiene. Esto implica una ampliación del ámbito de aplicación del principio de separabilidad a supuestos en que la potencial falta de eficacia, validez y operatividad del convenio de arbitraje no deriva ya de los defectos presentes en el contrato principal, sino del resultado de la interpretación sistemática de la cláusula de arbitraje.

27. Derivada de esta segunda cuestión surgiría una tercera que es el alcance del rol proactivo del interprete en la defensa de la validez de la cláusula o, dicho de otro modo, hasta dónde puede llegar el intérprete antes de admitir que las partes han podido errar en la configuración del arbitraje. En este

la rescisión de los contratos de fletamento, ante lo cual los fletadores solicitaron la suspensión del procedimiento judicial y la remisión de las partes al arbitraje convenido. En primera instancia, se rechazó la petición de suspensión del procedimiento judicial; sin embargo, en segunda instancia, la Corte de Apelación - Fiona Trust \& Holding Corporation and Other v Privalov and Others [2007] 2 Lloyd's Rep 267 - estimó la petición argumentando que, con base en el principio de separabilidad, la mera alegación de soborno en el contrato principal no servía para privar de eficacia a la cláusula de arbitraje. Planteado recurso ante la Cámara de los Lores, se ratificó el fallo de la Corte de Apelación. De conformidad con los fallos de la Corte de Apelación y de la Cámara de los Lores, como consecuencia del principio de separabilidad, para apreciar la falta de validez de la cláusula de arbitraje es necesario alegar y constatar un motivo directamente relacionado con la falta de validez de la propia cláusula, no siendo suficiente con alegar y demostrar la falta de validez del contrato en que se inserta dicha cláusula.

${ }^{39}$ El artículo 16(1) de la Ley Modelo recoge el principio de separabilidad a la hora de regular la facultad del órgano arbitral de decidir sobre su competencia, así dice: "El tribunal estará facultado para decidir acerca de su propia competencia, incluso sobre las excepciones relativas a la existencia o a la validez del acuerdo de arbitraje. A ese efecto, una cláusula compromisoria que forme parte de un contrato se considerará como un acuerdo independiente de las demás estipulaciones del contrato. La decisión del tribunal arbitral de que el contrato es nulo no entrañará ipso iure la nulidad de la cláusula compromisoria" (énfasis añadido). En el informe elaborado por el comité encargado de la redacción de la Ley de Arbitraje de 1996 explica en su informe que, considerando cuestiones diferentes el principio de separabilidad y la facultad del órgano arbitral a decidir sobre su jurisdicción, optaron por seguir la Ley Modelo pero desdoblando su contenido: mientras el artículo 7 de la Ley de Arbitraje de 1996 reconoce el principio de separabilidad - "Unless otherwise agreed by the parties, an arbitration agreement which forms or was intended to form part of another agreement (whether or not in writing) shall not be regarded as invalid, non-existent or ineffective because that other agreement is invalid, or did not come into existence or has become ineffective, and it shall for that purpose be treated as a distinct agreement" -, la facultad del órgano arbitral a pronunciarse sobre su jurisdicción se reconoce en el artículo 30 - "(1) Unless otherwise agreed by the parties, the arbitral tribunal may rule on its own substantive jurisdiction, that is, as to: (a) Whether there is a valid arbitration agreement; (b) Whether the tribunal is properly constituted; and (c) What matters have been submitted to arbitration in accordance with the arbitration agreement. (2) Any such ruling may be challenged by any available process of appeal or review or in accordance with the provisions of this Part" -.

40 "An arbitration agreement is a separate and distinct agreement and is not ordinarily impeached or rendered void if the substantive contract is discharged, frustrated, repudiated, rescinded, avoided or found to be void" [D. JosEPH, Jurisdiction and Arbitration Agreements and Their Enforcements (2nd edn, Sweet \& Maxwell 2010) para 4.36].

${ }^{41}$ B. Primrose, Separability and Stage One of the Sulamérica Inquiry (2017) 33 Arbitration International 139, 143. 
aspecto, en mi opinión, la solución adoptada en Sul América no incurre en un exceso: descartado el derecho brasileño como elección implícita por sus efectos sobre la eficacia del convenio de arbitraje, el tribunal acude al criterio residual de la conexión más estrecha y real, considerando que ésta era la ley del lugar designado como sede. Sin embargo, imaginemos que las pólizas hubieran previsto que la ley aplicable al procedimiento debía ser la ley brasileña, ¿hubiera esta previsión junto al resto de circunstancias presentes en el caso supuesto que ya no fuera la ley inglesa la que presentará una conexión más estrecha y real con el arbitraje? O, en sentido contrario, si las partes hubiera previsto un arbitraje en Brasil conforme a la normativa inglesa en materia de arbitraje, ¿podría considerarse que la elección de la ley inglesa como ley aplicable al procedimiento presenta una intensidad suficiente como para desplazar a una lex locus arbitri conforme a la cual la cláusula de arbitraje devendría ineficaz?

28. Por último, una cuarta cuestión se podría plantear en relación con Sul América y es si la elección de una sede no coincidente con el ordenamiento jurídico elegido expresamente como lex contractus no debería ser por si misma una indicación suficientemente intensa como para considerar que las partes nunca han tenido la intención de que resulte aplicable a la cláusula de arbitraje la misma ley que es aplicable al resto de cláusulas del contrato. Por ejemplo, en Sul América, sin necesidad de entrar a analizar las consecuencias que el sometimiento al derecho brasileño pudiera tener sobre la eficacia de la cláusula de arbitraje, ¿no parece que la elección de país diferente de Brasil como sede del arbitraje ya supone por si misma una indicación evidente de que las partes no quieren que la ley brasileña operase como lex arbitri?

29. Como veremos en los casos siguientes, algunas de estas cuestiones serán matizadas o enmendadas en los años posteriores por los tribunales de las jurisdicciones common law al aplicar la doctrina Sul América.

\section{Arsanovia Ltd \& Others v Cruz City 1 Mauritius Holdings [2013] 1 Lloyd's Rep 235}

30. En Junio del 2008, dos empresas - Arsanovia y Burley, subsidiarias ambas de Unitech-celebraron un contrato con Cruz City para el establecimiento de una joint venture cuyo objeto era el desarrollo de los suburbios de Bombay. Para lograrlo, Arsanovia y Cruz City constituyeron una sociedad denominada Kerrush Investments Ltd, que junto a Arsanovia y Cruz City suscribiría el 6 de junio del 2008 un acuerdo de accionistas que, además del sometimiento expreso del acuerdo a la ley india ${ }^{42}$, preveía un arbitraje institucional en Londres de las disputas que pudieran surgir entre las partes ante la LCIA - la Corte de Arbitraje Comercial Internacional de Londres - ${ }^{43}$. Paralelamente, el 6 de Junio de 2008, Burley, Unitech y Cruz City firmaron un acuerdo de respaldo financiero ${ }^{44}$ con idénticas cláusulas de arbitraje y de ley aplicable al contrato mediante el cual Unitech se comprometía a suministrar a Burley los fondos necesarios para que ésta pudiera cumplir con sus obligaciones económicas respecto al proyecto.

31. Con ocasión de la quiebra del accionista mayoritario de Cruz City, el 14 de Julio de 2010 Arsanovia remite a Cruz City dos notificaciones: en la primera le comunica que en cumplimiento del

\footnotetext{
${ }^{42}$ La cláusula 24 del acuerdo de accionistas decía lo siguiente: "Governing Law. This agreement shall be governed by, and construed in accordance with laws of India, without regard to the conflict of law rules thereof that would require the application of the laws of another jurisdiction".

43 "LCIA Arbitration. Any dispute arising out of or in connection with the provisions of this Agreement, including any question regarding its validity, existence or termination shall be referred to and finally settled by arbitration under the London Court of International Arbitration Rules ('Rules'), which rules are deemed to be incorporated by reference into this Clause. The number of arbitrators shall be three. The seat or legal place of the arbitration shall be London, England. The language to be used in the arbitral proceedings shall be English (...) Notwithstanding the above, the Parties hereto specifically agree that they will not seek any interim relief in India under the Rules or under the Arbitration and Conciliation Act 1996 (the 'Indian Arbitration Act'), including Section 9 thereof. The provisions of Part I of the Indian Arbitration Act are expressly excluded. For the avoidance of doubt, the procedure in this Clause 21 shall be exclusive procedure for the resolution of all disputes referred herein" (énfasis añadido) rezaba la cláusula 21 del acuerdo de accionistas.

${ }^{44}$ El acuerdo suscrito era uno de los denominados "Keepwell Agreements".
} 
acuerdo de accionistas ha perdido la capacidad de administración de su participación en Kerrush ${ }^{45}$; y, en la segunda, le traslada su obligación de vender a Arsanovia dicha participación conforme al procedimiento previsto en el acuerdo de accionistas ${ }^{46}$. Ante esta situación, el 13 de Septiembre de 2010, Cruz City pretende ejercitar la opción de venta prevista en el acuerdo de accionistas lo que supondría obligar a Arsanovia a pagar un importe más alto por la participación de Cruz City en Kerrush que el que debiera pagar bajo el procedimiento de venta forzosa incoado por Arsanovia mediante la notificación del 14 de Julio. Surge entonces una disputa entre las partes en relación con la validez de las notificaciones realizadas por Arsanovia en Julio ya que, si aquéllas son válidas, Cruz City no puede ejecutar la opción de venta.

32. La disputa derivó en tres arbitrajes ante la Corte de Arbitraje Comercial Internacional de Londres.

1. En el primer arbitraje Cruz City solicitaba que se condenase a Arsanovia y Burley al cumplimiento específico de la opción de compra y al pago de los daños y perjuicios ocasionados. Los demandados se limitaron a contestar impugnando la jurisdicción del órgano arbitral para conocer de la petición.

2. En el segundo arbitraje, Cruz City solicitaba que se condenase de conformidad con el acuerdo de respaldo financiero a Unitech y Burley al pago de daños y perjuicios. Los demandados se limitaron a contestar impugnando la jurisdicción del órgano arbitral para conocer de la petición.

3. Y, finalmente, en el tercer arbitraje Arsanovia solicitaba la adopción de un laudo en que se declarase la validez de las notificaciones de Julio de 2010 y la consiguiente condena a Cruz City a la venta de su participación en Kerrush conforme al procedimiento previsto en el acuerdo de accionistas. A esto respondió reconvencionalmente Cruz City repitiendo las peticiones realizadas en el primer arbitraje.

A pesar de ser resueltos por el mismo tribunal y escuchados en una misma audiencia, el tribunal no procedió a su acumulación, adoptándose tres laudos:

A. Respecto al primer arbitraje, el tribunal declaró ostentar jurisdicción y procedió a estimar la acción de Cruz City, declarando que Arsanovia no tenía derecho a realizar las notificaciones de julio y, por tanto, le condenó a comprar a Cruz City su participación en Karrush por el importe fijado conforme a la opción de venta y no conforme al procedimiento de venta forzosa previsto en el acuerdo de accionistas.

B. Respecto al segundo arbitraje, el tribunal declaró gozar de jurisdicción y obligó a Burley y Unitech a pagar cuánto se adeudará en relación con la opción de venta.

C. Respecto al tercer arbitraje, el tribunal desestimó tanto la demanda principal de Arsanovia como la reconvencional de City Cruz.

33. A la vista de los laudos, Arsanovia impugna la validez del primer y segundo laudo ante los tribunales ingleses aduciendo que los árbitros carecían de jurisdicción ${ }^{47}$ para conocer de las disputas de-

\footnotetext{
45 "Management approval termination notice" en inglés.

46 "Buy-Out Notice" en inglés.

${ }^{47}$ A diferencia del artículo 16 de la Ley Modelo, la Ley Inglesa de Arbitraje distingue por un lado el principio de separabilidad (artículo 7) y, por otro lado, la competencia del órgano arbitral a pronunciarse sobre su jurisdicción contemplada en el artículo 30. Éste artículo es especialmente importante porque en su primer apartado contiene la definición del concepto de jurisdicción substantiva - "Unless otherwise agreed by the parties, the tribunal may rule on its own substantive jurisdiction, that it is, as to: (a) whether there is a valid arbitration agreement; (b) whether the tribunal is properly constituted; and, (c) what matters have been submitted to arbitration in accordance with the arbitration agreement" [artículo 30(1) de la Ley Inglesa de Arbitraje de 1996] - que sirve de base para el mecanismo de impugnación del laudo previsto posteriormente en el artículo 67. Mediante la impugnación prevista en este artículo - que, junto a los previstos en los artículo 68 y 69, es uno de los medios de impugnación previstos en la Ley Inglesa de Arbitraje - se podrá impugnar en base a la falta de jurisdicción substantiva del tribunal tanto los laudos jurisdiccionales - es decir, aquellos sobre los que el órgano arbitral se pronuncia de manera preliminar y específica sobre su propia jurisdicción - como los laudos finales - entendiéndose estos por aquellos en los que se entra total o parcialmente a resolver el fondo del asunto. Ver: R.M Merkin \& L. FlanNerY, Arbitration Act 1996... op. cit. p. 101-113 y 291-303.
} 
bido a que, siendo aplicable a las cláusulas de arbitraje el derecho indio, conforme a éste no concurrían las circunstancias necesarias para que el órgano arbitral pudiera conocer de las disputas ${ }^{48}$. Por tanto, antes de entrar a decidir si el órgano arbitral carecía o no de jurisdicción, Smith J debe determinar si realmente la lex arbitri implícitamente elegida es la ley india - que es el derecho elegido expresamente por las partes como lex contractus - o si, por el contrario, resulta aplicable a la cláusula de arbitraje la ley inglesa - que es la lex locus arbitri -.

34. Recalcando que como consecuencia de la exclusión de los convenios de arbitraje del ámbito de aplicación del Reglamento Roma I, la determinación de la lex arbitri ha de realizarse conforme al common law, Andrew Smith J comienza recordando que éste marca que en primer término se atenderá a la elección expresa de las partes, no existiendo ésta a la elección implícita y, finalmente, en ausencia de elección expresa e implícita, se entenderá que la ley que presente una conexión más estrecha y real con el arbitraje debe operar como lex arbitri ${ }^{49}$.

35. Tras llevar a cabo un interesante análisis de las autoridades previas en la materia, siguiendo la doctrina Sul América, Andrew Smith J examina si existen indicaciones que conjuntamente consideradas puedan rebatir la presunción conforme a la cual la elección expresa del derecho indio como lex contractus conlleva su elección implícita como lex arbitri. Centrando su atención en que las cláusulas de arbitraje previstas tanto en el acuerdo de accionistas, como en el acuerdo de respaldo financiero, contienen tanto una renuncia expresa de las partes a la solicitud de adopción de medidas cautelares de conformidad con la normativa india en materia de arbitraje, como una exclusión de la Parte I de dicha normativa al arbitraje convenido ${ }^{50}$, Su Señoría concluye que dichas menciones denotan la asunción por las partes de que el derecho indio resultaba aplicable al arbitraje ${ }^{51}$. En consecuencia, más allá de la elección de Londres como sede, no aprecia otra indicación que apunte a que las partes no quisieran que el derecho expresamente elegido para regir el contrato no fuera también aplicable a la cláusula de arbitraje, considerando así que el derecho indio había sido implícitamente elegido como lex arbitri al ser expresamente elegido para regir los contratos que contenían las cláusulas de arbitraje ${ }^{52}$.

36. Finalmente, antes de entrar a analizar la ausencia de jurisdicción o no del órgano arbitral para adoptar los laudos impugnados, Smith J realiza un significativo comentario obiter dictae al recalcar que, de no haberse realizado la elección implícita del derecho indio, debería haber determinado la ley aplicable al convenio de arbitraje conforme al criterio residual de la conexión más estrecha y real con el arbitraje, en cuyo caso hubiera identificado como lex arbitri el derecho inglés al ser la lex locus arbitri la que presenta una conexión más estrecha y real con el arbitraje ${ }^{53}$.

\footnotetext{
${ }^{48}$ Representado por prestigioso barrister Jonathan Hirst, se aduce en ambos casos que, conforme al derecho indio, un órgano arbitral no puede conocer de una disputa que se plantea simultáneamente frente a varias partes cuando no todos los demandados son parte del convenio de arbitraje. En relación con el primer laudo se alega que Burley no es parte del convenio de arbitraje contemplado en el acuerdo de accionistas y, en consecuencia, el tribunal carecía de jurisdicción para conocer de la acción planteada contra Burley y Arsanovia. En relación con el segundo laudo se alega que Unitech no es parte del convenio de arbitraje previsto en el acuerdo de respaldo financiero, ergo, el tribunal carecía de jurisdicción para conocer de la acción planteada contra Burley y Unitech.

${ }^{49}$ Arsanovia Ltd \& Others v Cruz City 1 Mauritius Holdings [2013] 1 Lloyd's Rep 235 [8].

${ }^{50}$ Cómo se ha visto anteriormente, la cláusula 21.1 del acuerdo de accionistas disponía literalmente: "Notwithstanding the above, the Parties hereto specifically agree that they will not seek any interim relief in India under the Rules or under the Arbitration and Conciliation Act 1996 (the 'Indian Arbitration Act'), including Section 9 thereof. The provisions of Part I of the Indian Arbitration Act are expressly excluded. For the avoidance of doubt, the procedure in this Clause 21 shall be exclusive procedure for the resolution of all disputes referred herein" (énfasis añadido).

${ }^{51}$ Arsanovia Ltd \& Others v Cruz City 1 Mauritius Holdings [2013] 1 Lloyd's Rep 235 [20].

52 ibidem [21].

53 ibidem [24].
} 


\section{3. $B N A v B N B \& B N C$ [2019] SGCA 84}

37. El 7 de Agosto de 2012, BNA - una empresa china - celebra un contrato de compraventa con BNB - una empresa coreana - mediante el cual el primero se compromete a comprar cantidades específicas de un gas industrial que el segundo fabrica en una planta que dispone en China. Bajo el título "Disputas", la cláusula 14 del contrato contenía dos previsiones: por un lado, contenía una elección expresa del derecho chino como lex contractus ${ }^{54} \mathrm{y}$, por otro lado, previa para las disputas que pudieran surgir entre las partes un arbitraje institucional ante el SIAC - centro de arbitraje internacional de Singapur - en Shanghái ${ }^{55}$.

Posteriormente, al contrato principal se incorporó una adenda suscrita el 1 de Febrero de 2013 por BNA, BNB y BNC - una empresa china - cuya cláusula 2 disponía que a partir del 1 de Febrero de 2013 todos los derechos y obligaciones del vendedor en relación con el contrato de compraventa de gas industrial serían íntegramente asumidos por BNC. A su vez, la adenda aclaraba que debía ser considerada como una parte indivisible del contrato principal y que, en caso de discrepancia entre sus previsiones y el contrato, prevalecería la adenda.

38. No habiendo pagado BNA el precio por una de las entregas de gas, el 2 de Marzo de 2016 BNB y BNC presentaron una demandada de arbitraje ante el SIAC que fue contestada por BNA alegando la falta de jurisdicción del órgano arbitral por inexistencia de un acuerdo de arbitraje válido. De acuerdo con las alegaciones de BNA, el derecho aplicable al acuerdo de arbitraje era el derecho chino y conforme a éste, el acuerdo no era válido porque ni el derecho chino permite un arbitraje en China conforme a normas de instituciones extranjeras, ni permite que una disputa íntegramente doméstica pueda ser sometida a un arbitraje ante una institución extranjera.

39. Debiendo por tanto interpretar la cláusula de arbitraje y dilucidar si la ley china debía operar como lex arbitri, el órgano arbitral mediante un laudo adoptado el 18 de Julio de 2017 declaró ostentar jurisdicción. El razonamiento de los árbitros fue el siguiente:

A. La referencia realizada a Shanghái no debía entenderse en el sentido de que ésta fuera la sede del arbitraje porque, de serlo, conduciría a que la aplicación de la ley china y, consiguientemente, a que las partes hubieran confeccionado un acuerdo de arbitraje genuinamente inválido. En su lugar, la mayoría de los árbitros optaron por entender que la referencia a Shanghái consistía en la designación de esta ciudad china como mera localización de las audiencias y actuaciones arbitrales, siendo realmente la sede del arbitraje la ciudad de Singapur.

B. Como consecuencia de lo anterior, el órgano arbitral reconoció que la elección expresa de la ley china como lex contractus debía entenderse prima facie como una elección implícita de esa misma ley como ley aplicable a la cláusula de arbitraje; sin embargo, habida cuenta de que la cláusula devendría ineficaz de entenderse sometida a la ley china, la mayoría de los árbitros concluyeron que las partes no podían haber elegido implícitamente dicha ley como lex arbitri, debiéndose entonces determinar ésta conforme al criterio residual de la conexión más estrecha y real con el arbitraje. Siendo Singapur la sede, los árbitros entendieron que era su ley la que presentaba una conexión más estrecha y real con el arbitraje, debiendo por tanto actuar como lex arbitri.

${ }^{54}$ La cláusula 14.1 del contrato decía lo siguiente: "This Agreement shall be governed by the laws of the People's Republic of China".

${ }^{55}$ La cláusula 14.2 del contrato disponía: "With respect to any and all disputes arising out of or relating to this Agreement, the parties shall initially attempt in good faith to resolve all disputes amicably between themselves. If such negotiations fails, it is agreed by both parties that such disputes shall be finally submitted to the Singapore International Arbitration Centre (SIAC) for arbitration in Shanghai, which will be conducted in accordance with its Arbitration Rules. The arbitration award shall be final and binding on both parties". 
40. A la vista del laudo, BNA lo impugnó ante los tribunales de Singapur alegando la falta de jurisdicción del órgano arbitral ${ }^{56}$. La petición fue desestimada confirmándose así el razonamiento de la mayoría arbitral tanto en lo referente a la sede del arbitraje, como en lo relativo a la lex arbitri ${ }^{57}$. No compartiendo este fallo, se planteó entonces recurso ante la Corte de Apelación de Singapur que, como veremos, corregirá tanto la decisión arbitral como la judicial.

41. La Corte de Apelación comienza recordando que, a la hora de determinar en Singapur la ley aplicable a un acuerdo de arbitraje, se han de seguir los tres pasos marcados por la norma de conflicto del common law conforme a lo establecido en el caso $B C Y^{58}$ que incorpora en Singapur la doctrina del caso Sul América.

42. En consecuencia, lo primero que se pregunta el tribunal es si la elección expresa del derecho chino de la cláusula 14.1 del contrato podía entenderse como una elección expresa del derecho aplicable a la cláusula de arbitraje prevista en la cláusula 14.2. La Corte de Apelación lo descarta al considerar que ni del hecho de que ambas disposiciones formaran parte de la misma cláusula, ni del texto de la cláusula, se desprende la voluntad nítida de elección expresa del derecho chino como lex arbitri ${ }^{59}$.

43. Habiéndose descartado la elección expresa de lex arbitri, el siguiente paso es el análisis de la existencia o no de una elección implícita. Para ello, la Corte debe resolver un asunto preliminar fundamental: ¿constituye Shanghái una elección de sede o es únicamente la identificación del lugar dónde deben tener lugar las actuaciones arbitrales?

En este punto, la Corte de Apelación disiente de la decisión adoptada por el tribunal de primera instancia y por la mayoría del órgano arbitral. En mi opinión de manera acertada, siguiendo pronunciamientos de autoridades inglesas sobre cláusulas similares ${ }^{60}$, la Corte considera que la interpretación más natural de una cláusula que contiene una única referencia geográfica desemboca que sea ésta la que

${ }^{56}$ De conformidad con el artículo 10(3) de la Ley de Arbitraje Internacional de Singapur, la impugnación de los laudos jurisdiccionales - entendiéndose estos como las decisiones arbitrales adoptadas durante la sustanciación del procedimiento sobre su jurisdicción para conocer de la disputa - habrá de realizarse en el plazo de 30 días ante el tribunal de primera instancia - el High Court -. La decisión de este tribunal será susceptible de un recurso de apelación siempre y cuando sea autorizado por el órgano que adoptó la decisión recurrida [artículo 10(4)].

${ }^{57} B N A$ v BNB \& Another [2019] SGHC 142.

${ }^{58} B C Y$ v BCZ [2017] 3 SLR 357. Como consecuencia del caso BCY, casos como FirstLink Investments Corp Ltd v GT Payment Pte Ltd \& Others [2014] SGHCR 12 parece que han sido en cierta medida enmendados. En FirstLink las partes habían suscrito un contrato que contenía una cláusula que previa un arbitraje institucional ante el Instituto de Arbitraje de la Cámara de Comercio de Estocolmo. Lo más curioso del contrato es que, conteniendo una elección expresa de lex contractus, ésta no era una ley de un Estado, sino las normas del propio Instituto de Arbitraje de la Cámara de Comercio de Estocolmo; es decir, que al contrato resultaban aplicables las normas procedimentales que debían regir el desarrollo del arbitraje. Amparándose en Sul América, el demandante argumentaba que la elección expresa de lex contractus conllevaba la elección implícita de esa ley como lex arbitri y, por tanto, que las reglas institucionales debían regir la cláusula de arbitraje. De ser así, la cláusula resultaba nula por estar regido por unas normas meramente procedimentales. Reconociendo expresamente que no iba a seguir la doctrina Sul América, el tribunal de primera instancia de Singapur consideró que, a falta de indicaciones en sentido contrario, la elección de la sede debía entenderse como elección implícita de su derecho como ley aplicable al convenio de arbitraje. Por tanto, mientras al contrato resultaba aplicable las reglas de la institución sueca, al convenio de arbitraje le resultaba aplicable el derecho sueco por ser Estocolmo el lugar de la sede.

${ }^{59} B N A v B N B \& B N C$ [2019] SGCA 84 [59]. Con el debido respeto, en mi opinión, esta conclusión es errónea o, por lo menos, discutible. La cláusula 14 lleva por título "Disputas" lo cual ya indica claramente que lo que se contiene en la misma constituye un corpus regulatorio concerniente a la resolución de los problemas que pudieran surgir entre las partes. Teniendo en cuenta que su apartado 2 contiene el acuerdo de arbitraje, parecería lógico que la palabra "acuerdo" utilizada en el apartado 1 hiciera referencia al acuerdo de arbitraje que se prevé en el apartado siguiente dentro de la misma cláusula. Es decir, en mi opinión, como consecuencia de la interpretación conjunta de los dos apartados de la cláusula 14 se podría sostener que el apartado 1 contiene una elección expresa del derecho chino como lex arbitri. En cualquier caso, nada alteraría al fallo alcanzado por la Corte de Apelación ya que, como veremos a continuación, se determina que las partes han elegido implícitamente como lex arbitri la ley china.

${ }^{60}$ En Naviera Amazonica Peruana SA v Compania Internacional de Seguros del Peru [1988] 1 Lloyd's Rep 116, la Corte de Apelación concluyó que una cláusula que rezaba "arbitration in London" era una forma coloquial o habitual de indicar un arbitraje con sede en Londres. Esta interpretación se apoyó posteriormente en ABB Lummus Global Ltd v Keppel Fels Ltd [1999] 2 Lloyd's Rep 24 [31]. 
deba entenderse prima facie elegida como sede del arbitraje ${ }^{61}$. Por tanto, salvo que existieran indicios que apuntarán a lo contrario, mediante la fórmula "arbitration in Shanghai" las partes designaron a Shanghái como sede.

44. La cuestión subsiguiente consistía en determinar si la ineficacia del convenio de arbitraje derivada de dicha elección de sede podía ser considerada como un indicio suficientemente robusto como para rebatir la presunción de que el único lugar geográfico mencionado en la cláusula de arbitraje debía presuntamente entenderse como el lugar elegido como sede ${ }^{62}$. Como razonablemente alegaba la defensa de los apelados, de entenderse Shanghái como sede elegida por las partes, nada impediría que la ley china operara como lex arbitri y, por tanto, se produjera la paradoja de que las partes habían acordado arbitrar sus disputas al mismo tiempo que invalidaban dicho acuerdo ${ }^{63}$. La Corte de Apelación considera que para que esta alegación pudiera ser estimada se debería constatar que las partes eran al menos conscientes de que la validez del acuerdo de arbitraje podía verse afectada por la elección de lex arbitri; sin embargo, no existía prueba alguna de que las partes hubieran sido en momento alguno conscientes de las consecuencias de la interacción entre el derecho chino y la elección de una institución arbitral extranjera, ni de los efectos que la combinación de estos elementos tendría sobre la validez de la cláusula de arbitraje ${ }^{64}$.

45. Habiéndose establecido que la cláusula de arbitraje designaba Shanghái como sede, no existía motivo alguno que impidiera concluir que la elección expresa de la ley china como lex contractus debía entenderse a su vez como elección implícita de esa misma ley como lex arbitri. De esta forma, sin necesidad de acudir al criterio residual de la conexión más estrecha y real, la Corte de Apelación estimaba el recurso y dictaminaba que la ley aplicable al acuerdo de arbitraje era la ley china ${ }^{65}$.

46. A título de cierre, la Corte de Apelación hizo referencia a la tercera de las cuestiones que suscitaba Sul América, la referida a los límites en el papel proactivo del interprete. Ya al comienzo de su sentencia, la Corte había avisado de que el hecho de que convenio surgiera de un acuerdo entre las partes no significaba que debiera ser en todo caso válido ${ }^{66}$. Incidiendo en esta idea, en el último párrafo de la sentencia, la Corte recalca que la existencia de una voluntad expresa de las partes no significa que ésta deba llevarse a cabo a toda costa. A su parecer, la interpretación de la cláusula debe realizarse de manera que a los términos utilizados en su redacción se les otorgue su sentido natural. Si el resultado de

\footnotetext{
${ }^{61} B N A v B N B \& B N C$ [2019] SGCA 84 [65].

${ }^{62}$ La Corte de Apelación de Singapur apoya su decisión en el interesante caso inglés Shagang South-Asia (Hong Kong) Trading Co Ltd v Daewoo Logistics [2015] EWHC 194 (Comm). Éste trata de un contrato de fletamento que, por un lado, tiene una cláusula que dice "Arbitraje: el arbitraje tendrá lugar en Hong Kong. Será aplicada la ley inglesa” y, por otro, prevé la incorporación por referencia de los términos del modelo estandarizado de contrato de fletamento Gencon 1994 cuya cláusula 19 prevé de forma genérica un arbitraje en Londres conforme a la normativa inglesa en arbitraje. Conociendo de una impugnación de un laudo adoptado en Londres a raíz de una disputa entre las partes, el High Court debe decidir si Hong Kong es la sede y la mención a la ley inglesa hace referencia a la normativa a aplicar al fondo del asunto o si, por el contrario, la mención a la ley inglesa hace referencia a la ley aplicable al procedimiento y, consiguientemente, supone una elección implícita de Inglaterra como sede de arbitraje, siendo entonces Hong Kong únicamente lugar de celebración de las sesiones. El Tribunal se decantó finalmente por la primera opción argumentando que, desde una perspectiva mercantil, la interpretación más lógica apuntaba a que la fórmula "arbitration to be held in Hong Kong" implicaba que la antigua colonia Británica era el lugar elegido como sede y, en consecuencia, que a falta de indicaciones que claramente apuntaran a lo contrario, se debía presumir que la ley de Hong Kong debía operar también como ley aplicable al procedimiento arbitral. Esto conllevaba que la segunda parte de la cláusula prevista en el contrato - que rezaba "English Law to be applied" - debía entenderse en el sentido de que ésta era la ley que debía ser aplicada al fondo del asunto.

${ }^{63} B N A v B N B \& B N C$ [2019] SGCA 84 [89].

${ }^{64}$ ibidem 90

${ }^{65}$ ibidem 94.

66 "An arbitration agreement by definition is the product of negotiations between the parties. By incorporating an arbitration agreement into an underlying contract, the parties contemplate that should a dispute arise, it should be referred to arbitration strictly in accordance with the terms of the arbitration agreement and no more. However, it does not follow that the parties' manifest intention to arbitrate must always be given effect to come what may. Ultimately, whether the parties' intention to arbitrate should be enforced invariably depends on the wording and proper construction of the arbitration agreement. What must not be overlooked is that arbitration agreements, despite the best intention of the parties, can at times be invalid for any one of a variety of reasons (...)" [ibidem 1-2].
} 
esta interpretación conlleva que el convenio de arbitraje es nulo, ineficaz o inexistente, deben las partes asumir sus consecuencias ${ }^{67}$.

\section{La elección de la sede como elección implícita de ley aplicable a la cláusula de arbitraje: Enka Insaat Ve Sanayi AS v OOO Insurance Company Chubb \& Others [2020] EWCA Civ 574}

\section{Hechos}

47. En relación con la construcción en Rusia de una planta eléctrica para la empresa Unipro, en Mayo de 2011 Enka - una empresa turca dedica a la realización de trabajos internacionales de construcción e ingeniería - fue subcontratada por CJSC Energoproekt para la realización del diseño y construcción de una parte de la planta. En la cláusula 50.1, bajo el título "Resolución de Disputas", el contrato preveía que las disputas entre las partes debían someterse a un arbitraje conforme a las reglas de la Cámara Internacional de Comercio con sede en Londres ${ }^{68}$.

El 21 de Mayo de 2014 CJSC, Unipro y Enka suscribieron un acuerdo mediante el cual los derechos y obligaciones de CJSC en relación con el contrato suscrito con Enka serían asumidos íntegramente por Unipro. El acuerdo disponía en su cláusula 7.5 que cualquier disputa que surgiera entre Enka y Unipro debería resolverse mediante un arbitraje conforme a lo previsto en la cláusula 50.1 del contrato de Mayo del 2011.

48. El 1 de Febrero de 2016 un incendio arrasó la planta y Unipro reclamó contra su aseguradora una indemnización. Entre Noviembre del 2016 y Mayo del 2017, la aseguradora Chubb pagó a Unipro una indemnización de más de 26.000 millones de Rublos - algo más de 400 millones de dólares -, lo que supuso su subrogación en los derechos que pudiera tener Unipro frente a Enka y otros contratistas por su posible responsabilidad en el incendio.

49. El 23 de Septiembre de 2017, la aseguradora Chubb comunicó a Enka que se había podido constatar que el incendio era consecuencia de defectos presentes en las tuberías de combustible atribuibles a la falta de calidad del trabajo efectuado por Enka lo que les hacía responsables del incendio.

50. A pesar de la existencia de la cláusula 50.1, la aseguradora instó en Mayo del 2019 un arbitraje en Moscu que llevo a Enka a solicitar ante los tribunales ingleses la adopción de unas anti-suit injunctions que compelieren a la aseguradora a renunciar al procedimiento de arbitraje comenzado en

67 "The essential point we make is that the parties' manifest intention to arbitrate is not to be given effect at all costs. The parties did not only choose to arbitrate - they chose to arbitrate in a certain way, in a certain place, under the administration of a certain arbitral institution. Those all have to be given effect by a process of construction which critically gives the words of the arbitration agreement their natural meaning, unless there are sufficient contrary indicia to displace that reading. If the result of this process of construction is that the arbitration agreement is unworkable, then the parties must like with the consequences of their decision" [ibidem 104].

${ }^{68}$ La cláusula decía lo siguiente: "The Parties undertake to make in good faith every reasonable effort to resolve any dispute or disagreement arising from or in connection with this Agreement (including disputes regarding validity of this agreement and the fact of its conclusion (hereinafter - "Dispute") by means of negotiations between themselves. In the event of the failure to resolve any Dispute pursuant to this Article within 10 (ten) days from the date that either Party sends a Notification to the opposite Party containing an indication of the given Dispute (the given period may be extended by mutual consent of the Parties) any Party may, by giving written notice, cause the matter to be referred to a meeting between the senior managements of the Contractor and Customer (in the case of the Contractor senior management should be understood as a member of the executive board or above, in the case of Customer, senior management shall be understood as general directors of their respective companies). The parties may invite the End Customer to such Senior Management Meeting. Such meeting should be held within fourteen (14) calendar days following the giving of a notice. If the matter is not resolved within twenty (20) calendar days after the date of the notice referring the matter to appropriate higher management or such later date as may be unanimously agreed upon, the Dispute shall be referred to international arbitration as follows:(a) the Dispute shall be finally settled under the Rules of Arbitration of the International Chamber of Commerce, (b) the Dispute shall be settled by three arbitrators appointed in accordance with these Rules, (c) the arbitration shall be conducted in the English language, and (d) the place of arbitration shall be London, England". 
Rusia y avenirse a lo acordado en el contrato. En primera instancia, amparándose en el forum non conveniens, el tribunal inglés no estimó la petición, lo que llevo a la empresa turca a recurrir esta decisión ante la Corte de Apelación, la cual con su decisión vendrá no solamente a corregir la decisión adoptada en primera instancia, sino también a modificar la doctrina sentada en el caso Sul América nueve años antes.

\section{Fallo de la Corte de Apelación}

51. Siendo una de las cuestiones a resolver la identificación de la lex arbitri, las partes se muestran de acuerdo en que la ley aplicable al contrato es la rusa, pero mientras Enka aduce que la ley aplicable al convenio de arbitraje es el derecho inglés, Chubb asegura que es el derecho ruso.

52. En primer lugar, Popplewell LJ - el magistrado ponente con el que estarán de acuerdo sus compañeros de sala: Males LJ y Flaux LJ -, siguiendo el fallo adoptado por la Corte de Apelación en Kabab-Ji $S A L$ (Lebanon) v Kout Food Group (Kuwait) ${ }^{69}$, dispone que la elección expresa de una lex arbitri no tiene necesariamente que contenerse en la misma cláusula arbitral, sino que puede contemplarse o desprenderse de otra cláusula del contrato como puede ser aquélla en que se elige expresamente la lex contractus $^{70}$.

En este aspecto, por tanto, la Corte de Apelación aclara una de las cuestiones examinadas anteriormente que suscitaba Sul América y sobre la que la Corte de Apelación de Singapur en BNA parecía mostrarse más restrictiva.

53. En segundo lugar, Popplewell LJ considera que el principio de separabilidad, sin llegar a producir el aislamiento de la cláusula de arbitraje, no sería únicamente aplicable a aquellos supuestos en que se ponga en cuestión la validez, eficacia o existencia del contrato principal, sino que también debe entrar en funcionamiento cuando, siendo necesario determinar la lex arbitri, las partes hayan optado por una sede y, en consecuencia, una lex locus arbitri diferente de la ley aplicable al contrato ${ }^{71}$.

Esto supone que, en aquellos supuestos en que la sede no se ubique dentro del territorio de la ley elegida expresamente como lex contractus, la determinación de la ley implícitamente elegida por las partes para regir la cláusula de arbitraje habrá de realizarse sobre la premisa de que la cláusula es independiente del resto del contrato.

Como consecuencia de esto, la Corte de Apelación reconoce expresamente que la presunción de Sul América conforme a la cual la elección expresa de lex contractus conlleva una elección implícita de lex arbitri vería circunscrita su aplicabilidad a aquellos supuestos en que la cláusula de arbitraje designe como sede el mismo Estado cuya ley ha sido elegida expresamente para regir el contrato en que se inserta la cláusula de arbitraje ${ }^{72}$. En realidad, como consecuencia de este ámbito reducido de aplicación y de lo que se verá en el párrafo siguiente, en realidad la presunción de Sul América carecerá ya de relevancia y la elección expresa de lex contractus lo único que hará es reforzar la presunción de que es la lex locus arbitri la elegida implícitamente por las partes.

54. En tercer y último lugar, atendiendo a la relación tan estrecha existente entre la lex arbitri y la lex locus arbitri, la Corte de Apelación considera que, a falta de una indicación en sentido contrario,

\footnotetext{
${ }^{69}$ Kabab-Ji SAL (Lebanon) v Kout Food Group (Kuwait) [2020] EWCA Civ 6. En este caso, una empresa libanesa y una kuwaití celebraron un contrato que mientras su artículo 1 disponía que el contrato debía ser considerado como una unidad - "It shall be construed as a whole and each of the documents mentioned is to be regarded as an integral part of this Agreement and shall be interpreted as complementing the others" -, el 14 preveía un arbitraje en Paris conforme a las reglas de la cámara internacional de comercio y el 15 contenía una elección expresa del derecho inglés como lex contractus - "This Agreement shall be governed by and construed in accordance with the laws of England" -. Desestimando la apelación, la Corte de Apelación consideró que la interpretación conjunta de los artículos 1 y del 15 indicaba nítidamente que las partes no solamente habían elegido el derecho inglés como ley aplicable al contrato, sino también a la cláusula de arbitraje del artículo 14. En sentido contrario se ha pronunciado posteriormente la Corte de Apelación de Paris: Kabab-Ji S.A.L. Company v Kout Food Group Company Cour d'Appel de Paris (Arrêt du 23 Juin 2020).

${ }^{70}$ Enka Insaat Ve Sanayi AS v OOO Insurance Company Chubb \& Others [2020] EWCA Civ 574 [88] - [90].

${ }^{71}$ ibidem [94].

72 ibidem [95].
} 
resulta difícil imaginar que las partes de un convenio opten por una ley aplicable al convenio de arbitraje diferente de la ley del lugar elegido como sede. Por ello, la elección de sede debe entenderse presuntamente como una elección implícita de la ley aplicable a la cláusula arbitral ${ }^{73}$. La Corte de Apelación reconoce que esta presunción podrá ser rebatida por las diferentes circunstancias que puedan concurrir en cada caso - por ejemplo, expresamente se cita en el fallo la falta de validez del convenio conforme a la lex locus arbitri -, pero recalca que dichas circunstancias habrán de ser extraordinariamente poderosas para que se deje de considerar que las partes han querido que ley de la sede y la ley aplicable al convenio sean la misma ${ }^{74}$.

\section{Fallo del Tribunal Supremo del Reino Unido}

55. En un fallo aprobado por una ajustada mayoría de 3 contra $2^{75}$, el Tribunal Supremo del Reino Unido corrige la decisión de la Corte de Apelación y, en un sentido análogo a como lo hizo Moore-Bick LJ en Sul América, fija los pasos que han de guiar la determinación de la ley aplicable a una cláusula de arbitraje.

56. El punto central del fallo de la mayoría es el rechazo al que denomina "argumento del solapamiento" "76 utilizado por la Corte de Apelación y conforme al cual, dada la estrecha relación existente entre la ley aplicable al procedimiento arbitral y la lex arbitri, la elección de lex contractus no abarcaría la cláusula de arbitraje en aquellos casos en que la ley elegida por las partes fuera diferente de la que resultara aplicable al procedimiento arbitral ${ }^{77}$.

Considerando exorbitante la aplicabilidad del principio de separabilidad defendida por la Corte de Apelación ${ }^{78}$, el Tribunal Supremo rechaza que pueda tratarse la cláusula de arbitraje como un acuerdo independiente del resto del contrato cuando exista falta de identidad entre la lex locus arbitri y la lex contractus. En su lugar, el Tribunal defiende que la elección de una ley aplicable al contrato debe entenderse en su sentido natural ${ }^{79}$, lo que supondrá que, salvo indicio en contrario, las partes al elegir la ley aplicable al contrato pretendían que esa misma ley se aplicase también a la cláusula de arbitraje ${ }^{80}$.

57. En segundo lugar, teniendo en cuenta la máxima "verba ita sunt intelligenda ut res magis valeat quam pereat"s1, el Tribunal Supremo defiende que la interpretación de la cláusula de arbitraje habrá

${ }^{73}$ Ibidem [96] - [102].

${ }^{74}$ ibidem [104].

${ }^{75}$ El voto particular suscrito por los dos magistrados discrepantes no comparte principalmente que haya ausencia de elección del derecho ruso como lex contractus. Mientras la mayoría de la sala considera que la ley aplicable al contrato habría de determinarse de conformidad con el artículo 4 del Reglamento Roma I, la minoría considera que el derecho ruso ha sido elegido implícitamente, conforme a lo previsto en el artículo 3(1) del Reglamento (Enka Insaat Ve Sanayi AS v OOO Insurance Company Chubb \& Others [2020] UKSC 38 [205] y [207]). Esto conlleva que, compartiendo con la mayoría de la sala que la ley elegida como lex contractus ha de entenderse con carácter general como implícitamente elegida como ley aplicable a la cláusula de arbitraje, en el caso concreto, la lex arbitri debería ser el derecho ruso (ibidem [228] y [229]). Por otro lado, aun admitiendo que pudieran estar equivocados sobre la elección implícita del derecho ruso como lex contractus, el voto discrepante sostiene que, de identificar la ley aplicable al contrato conforme al criterio residual de la conexión más estrecha y real, éste conllevaría igualmente la aplicación del derecho ruso (ibidem [256]). Así, no considerando proporcionada la relevancia que se le da a la elección de sede en los supuestos de falta de elección expresa o implícita de lex arbitri (ibidem), la minoría sostiene que la aplicabilidad del derecho ruso como lex contractus habría de prevalecer sobre la elección de Londres como sede del arbitraje (ibidem [260]).

76 "Overlap Argument" en palabras del Tribunal Supremo del Reino Unido.

${ }^{77}$ En palabras del Tribunal Supremo, el argumento del solapamiento "rests on the premise that the curial law which governs the arbitration process is so closely related to the law governing the arbitration agreement that a choice of law to govern the contract should generally be presumed not to apply to an arbitration clause when the parties have chosen a different curial law" (Enka Insaat Ve Sanayi AS v OOO Insurance Company Chubb \& Others [2020] UKSC 38 [64]).

78 ibidem [61].

79 ibidem [43].

${ }^{80}$ ibidem [60] y [53].

${ }^{81}$ Máxima reconocida en el derecho inglés desde 1626 y traducida por STAUGHTON en Lancashire County Council v Municipal Mutual Insurance Ltd [1997] QB 897 como "the contract should be interpreted so that it is valid rather tan ineffective" 
de hacerse en el sentido más favorable a su validez, existencia o efectividad. En consecuencia, cuando conforme a la ley elegida como lex contractus la cláusula de arbitraje fuera inválida, ineficaz o inexistente habrá de interpretarse esta circunstancia como un indicio en contra de que las partes quisieran que dicha ley operará como lex arbitri ${ }^{82}$.

Por tanto, la falta de validez, existencia o eficacia de la cláusula de arbitraje conforme a la lex contractus elegida por las partes constituirá una excepción a la presunción de que la ley elegida como lex contractus ha de entenderse implícitamente elegida como ley aplicable a la cláusula de arbitraje.

58. En tercer lugar, reconociendo que de la elección de sede se puede inferir una voluntad de que su derecho condicione en cierta medida la validez y extensión del convenio de arbitraje ${ }^{83}$, el Tribunal Supremo admite que la elección de una sede cuya ley disponga que, a falta de elección expresa de lex arbitri, ésta habrá de ser la lex locus arbitri ${ }^{84}$, será otro indicio en contra de la presunción de que las partes implícitamente deseaban que la ley elegida como lex contractus operara como ley aplicable a la cláusula de arbitraje ${ }^{85}$.

59. En cuarto lugar, descartada la elección implícita de aquella ley elegida como lex contractus, deberá entenderse que la ley aplicable a la cláusula de arbitraje será aquélla que presente una conexión más estrecha y real con el arbitraje, siendo generalmente ésta la ley del lugar de la sede ${ }^{86}$.

La aplicación de este criterio residual también tendrá lugar en aquellos supuestos en que el contrato carezca de una elección de lex contractus.

59. La aplicación de lo hasta aquí analizado al caso concreto supone que, no habiendo las partes elegido la ley aplicable al contrato ${ }^{87}$ y previendo la cláusula un arbitraje en Londres, en aplicación del criterio residual de la conexión más estrecha y real, el Tribunal Supremo concluye que debe ser la ley in-

(énfasis añadido) - es decir, "el contrato debe ser interpretado para que éste sea válido y no ineficaz" -. La máxima ha sido aplicada en numerosos casos. Por ejemplo, en In re Missouri Steamship Co (1889) 42 Ch D 321, un caso concerniente al derecho aplicable a un contrato de transporte de ganado desde Boston a Inglaterra que contenía una cláusula nula de ser aplicable el derecho de Massachussets, el tribunal aplicó la máxima para concluir que las habían sometido el contrato al derecho inglés porque únicamente conforme a éste la totalidad de las cláusulas del contrato serían válidas. Igualmente, en Hamlyn v Talisker [1894] AC 202, un caso relativo al derecho aplicable a una cláusula de arbitraje en Londres contenida en un contrato entre una empresa inglesa y una escocesa, la Cámara de los Lores unánimemente enmendó la sentencia que consideraba que siendo aplicable al contrato el derecho escocés por ser en Escocia dónde debía ejecutarse el contrato, aquél debía aplicarse también a la cláusula de arbitraje y, por tanto, la cláusula era nula al no identificarse los árbitros que debían resolver la disputa. La Cámara de los Lores consideró que la combinación de la elección de Londres como sede y la obligación de que los árbitros pertenecieran a una determinada institución inglesa conllevaba que las partes habían querido que el derecho inglés fuera el aplicable. En apoyo a esta conclusión, la Cámara de los Lores aducía que no podía haber sido la intención de las partes someter la cláusula de arbitraje y el contrato al derecho escocés porque conforme a éste la cláusula de arbitraje sería nula de pleno derecho y, por tanto, ante la duda, debía interpretarse de la manera más favorable a su efectividad.

${ }^{82}$ Enka Insaat Ve Sanayi AS v OOO Insurance Company Chubb \& Others [2020] UKSC 38 [108]

${ }^{83}$ En este punto, el Tribunal Supremo parece respaldar la interpretación del High Court en Carpatky Petroleum Corporation v PJSC Uknafta [2020] EWHC 769 (Comm). Este caso concernía el reconocimiento y ejecución de un laudo adoptado en Suecia cuya nulidad alegaba el ejecutado al considerar que, siendo aplicable al convenio de arbitraje el derecho ucraniano, el convenio de arbitraje era nulo. Estimando de la elección de Suecia como sede se podía inferir una voluntad de las partes de que fuera la Ley Sueca la que rigiera aspectos tales como el alcance de la elección de las partes o la validez del acuerdo de arbitraje, el High Court concluyó que, al elegir Suecia como sede del arbitraje, las partes querían que se aplicará a su arbitraje el artículo 48 de la Ley Sueca de Arbitraje. Esto suponía que, no existiendo elección expresa de lex arbitri, se debería aplicar al convenio de arbitraje la lex locus arbitri, es decir, la ley sueca.

${ }^{84}$ Esto ocurre, por ejemplo, en el artículo 6 de la Ley Escocesa de Arbitraje o en el artículo 48 de la Ley Sueca de Arbitraje. Ver: R. NAzzINI, The law applicable ... op. cit. p. 685-686 y A. REDFERn, Redfern \& Hunter: Law... op. cit. párrafos 3.25-3.36.

${ }^{85}$ Enka Insaat Ve Sanayi AS v OOO Insurance Company Chubb \& Others [2020] UKSC 38 [70] - [72].

${ }^{86}$ ibidem [120].

87 "In these circumstances, it cannot be said that the parties have in the construction contract expressly selected a system of law to govern the validity and interpretation of their contractual obligations nor that the terms of the contract construed in their context point ineluctably to the conclusion that the parties intended Russian law to apply. To the contrary, the obvious inference from the fact that the parties have not anywhere in the contract stated what system of law is to govern any of their contractual obligations (...) is that they have not agreed (for whatever reason) on a choice of governing law" (ibidem [155]). 
glesa la que opere como ley aplicable a la cláusula de arbitraje ${ }^{88}$. En consecuencia, el Tribunal Supremo llega a la misma conclusión que la Corte de Apelación, pero por un camino diferente.

\section{Análisis crítico}

60. La principal incógnita que suscitaba la sentencia de la Corte de Apelación era su aproximación al principio de separabilidad de la cláusula de arbitraje. Lejos de seguir el canon clásico examinado anteriormente que circunscribía su aplicabilidad a casos en que existieran circunstancias que afectaran a la validez sustancial del contrato en que se inserta la cláusula, la Corte de Apelación defendía una separabilidad a los efectos de determinar los elementos que pueden a afectar a la validez, eficacia y existencia de la cláusula de arbitraje, siendo uno de ellos su lex arbitri ${ }^{89}$.

La principal ventaja que ofrecía esta aproximación es que, debiéndose analizar aisladamente la cláusula con respecto al resto del contrato, la determinación de la lex arbitri de una cláusula venía únicamente condicionada por aquellos elementos presentes en la propia cláusula. Esto además suponía que, descartada la interpretación sistemática de la cláusula de arbitraje, la norma de conflicto del common law se aplicaba de la misma forma a una cláusula de arbitraje y a un acuerdo de arbitraje.

No obstante, ampliando exageradamente su ámbito de aplicación, la Corte de Apelación distorsionaba el principio de separabilidad, haciéndolo además de manera un tanto arbitraria, ya que defendía que el análisis aislado de la cláusula únicamente debía tener lugar cuando las partes hubieran elegido una lex contractus diferente de la ley del lugar elegido como sede. Puestos a ampliar el ámbito de aplicación del principio de separabilidad, ¿por qué no analizar aisladamente la cláusula también cuándo las partes no tuvieran su domicilio en el lugar de la sede o cuando la disputa presentará una mayor conexión real con un Estado diferente de aquél en que se ubique la sede del arbitraje?

Por ello, en mi opinión, el Tribunal Supremo acierta al censurar la aplicación realizada por la Corte de Apelación del principio de separabilidad con base en el que denomina argumento del solapamiento.

61. La consecuencia inmediata de lo que se acaba de analizar es el restablecimiento del criterio de interpretación sistemática de la cláusula y, consiguientemente, de la presunción de que, a falta de indicación en contrario, la elección de lex contractus conllevará que esa misma ley se entienda implícitamente elegida por las partes como ley aplicable a la cláusula de arbitraje.

A efectos de la aplicabilidad de la presunción, tanto del fallo de la mayoría de la sala, como del voto particular de Lord Burrows y Lord Sales, se desprende una aclaración importante al considerar que la presunción no se aplicará únicamente en aquellos supuestos en que las partes hayan elegido expresamente la ley aplicable al contrato, sino también en aquellos supuestos en que la elección resulte de manera inequívoca de los términos del contrato o de las circunstancias del caso. En consecuencia, existiendo una elección de lex contractus conforme al artículo 3 Reglamento Roma I, se aplicará la presunción. No existiendo ésta y debiéndose determinar la ley aplicable al contrato conforme a criterios residuales como los previstos en los artículos 4 o 5 del Reglamento, no se aplicará la presunción y será

\footnotetext{
ibidem [156].

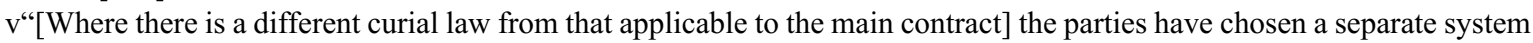
of law to govern one aspect of their relationship, namely the curial law of the arbitration agreement. The arbitration agreement is treated as separate and severable for the purposes of this choice of curial law, about which the main contract has nothing to say. Why then should it have anything to say about the closely related aspect of the very same arbitration agreement, namely the [lex arbitri] (absent express language to that effect as to give rise to an express choice of [lex arbitri]? Moreover, questions of the validity, existence and effectiveness of an arbitration agreement are often governed by the [lex arbitri], under which they fell to be determined. If the arbitration agreement is properly isolated from the main contract by the doctrine of separability for the purpose of one aspect governed by the [lex arbitri], namely its validity, existence and effectiveness, that is a powerful indication that it is to be isolated for the purpose of determining the [lex arbitri] more generally. In other words, because parties are to be treated as having contracted on the basis that the main contract and the arbitration clause are separate and distinct agreements for the purposes of the latter's validity, existence and effectiveness, so they should be taken as having contracted on the same basis in respect of the governing law of the arbitration agreement which determines its validity, existence and effectiveness" (Enka Insaat Ve Sanayi AS v OOO Insurance Company Chubb \& Others [2020] EWCA Civ 574 [94]).
} 
aplicable a la cláusula de arbitraje la ley que presente una conexión más estrecha y real con el arbitraje, siendo ésta generalmente la lex locus arbitri ${ }^{90}$.

Asimismo, el fallo del Tribunal perfila las excepciones a la presunción de manera más nítida que sus antecesores. En primer lugar, el Tribunal reconoce que la presunción no se aplicará en aquellos supuestos en que conforme a la lex contractus la cláusula de arbitraje devendría ineficaz, inexistente o inválida. Esto lo hace evitando la aplicación del principio de separabilidad, algo que muchas veces se había sugerido que realizó la Corte de Apelación en el caso Sul América. Y, en segundo lugar, el Tribunal admite una excepción no reconocida en los casos en que se había aplicado la doctrina del caso Sul América: la posible inaplicación de la lex contractus cuando la lex locus arbitri prevea una norma de conflicto conforme a la cual, a falta de elección expresa de lex arbitri, deba aplicarse a la cláusula de arbitraje la ley del lugar elegido por las partes como sede.

Por tanto, en mi opinión, el fallo del Tribunal Supremo también acierta en el restablecimiento de la interpretación sistemática de la cláusula de arbitraje y en la delimitación de la aplicabilidad de la presunción de que elegida una lex contractus, ésta debe entenderse implícitamente elegida como ley aplicable a la cláusula de arbitraje.

62. Por último, a pesar de que el Tribunal Supremo alega que los pasos que fija para el esclarecimiento de la ley aplicable a la cláusula de arbitraje encuentran mejor acomodo en el marco del Arbitraje Comercial Internacional que los previstos en el fallo de la Corte de Apelación ${ }^{91}$, lo cierto es que al amparo tanto del derecho internacional ${ }^{92}$, como del derecho comparado ${ }^{93}$, no resulta exótico considerar como hizo la Corte de Apelación que, a falta de elección expresa de lex arbitri, debe aplicarse a la cláusula de arbitraje la lex locus arbitri, no la ley elegida para el contrato.

\section{Conclusiones}

63. Las normas de conflicto del common law disponen que la determinación de la ley aplicable a un convenio de arbitraje habrá de determinarse en tres fases: en primer lugar, se atenderá a la elección

\footnotetext{
${ }^{90}$ En este punto, como se ha referido anteriormente, estriba una de las diferencias entre la postura mantenida por el voto particular y el fallo mayoritario. Mientras el primero sostiene que sí existía una elección del derecho ruso en los términos del artículo 3 del Reglamento Roma I, el segundo considera que no, debiéndose determinar la ley aplicable al contrato conforme a lo previsto en el artículo 4.

${ }^{91}$ Enka Insaat Ve Sanayi AS v OOO Insurance Company Chubb \& Others [2020] UKSC 38 [55] - [58] y [125] - [141].

${ }^{92} \mathrm{El}$ artículo V(1)(a) de la Convención de Nueva York prevé que el reconocimiento y ejecución del laudo se podrá denegar cuando el convenio de arbitraje "no es válido en virtud de la ley a que las partes lo han sometido, o si nada se hubiera indicado a este respecto, en virtud de la ley del país en que se haya dictado [el laudo]". Esta disposición se considera una norma de conflicto que determinar que, a falta de elección - que la doctrina anglosajona entiende que no solamente puede ser expresa, sino también implícita - de lex arbitri, se entenderá que la ley aplicable al convenio de arbitraje será le lex locus arbitri. En este sentido, algo más completa es la norma de conflicto prevista en el artículo VI(2) del Convenio Europeo sobre Arbitraje Comercial Internacional de 1961 que, junto a las normas referidas en el artículo V(1)(a) de la Convención de Nueva York, añade una tercera norma para los casos en que no se pudiera determinar la sede del arbitraje, debiéndose entonces aplicar por la autoridad judicial encargada de decidir sobre la validez del convenio de arbitraje la ley que determinen sus normas de conflicto

${ }^{93}$ Como ya se ha indicado anteriormente, por ejemplo, de manera análoga al artículo 6 de la Ley Escocesa de Arbitraje, el artículo 48 de la Ley Sueca de Arbitraje prevé que, a falta de designación expresa de una ley aplicable al convenio de arbitraje, se aplicará la ley del lugar dónde el arbitraje haya tenido o deba tener lugar. Por ello, no sorprende que en Bulgarian Foreign Trade Bank Ltd v AI Trade Finance Inc Högsta Domstolens (No 1881-99, 27/10/2000) - un caso concerniente a una impugnación de un laudo dictado en Estocolmo a raíz de una cláusula de arbitraje en dicha ciudad prevista en un contrato sometido expresamente al derecho austriaco - el Tribunal Supremo Sueco dictaminará que, a falta de elección de lex arbitri, la falta de validez de la cláusula de arbitraje se debía determinar de conformidad con el derecho sueco, la lex locus arbitri. En similar sentido, se pronunció la justicia belga en Matermaco SA v PPM Cranes Inc (2000) 25 YBCA 641 al considerar el Tribunal de l'Enterprise de Bruxelles que, a pesar de que las partes habían elegido expresamente como lex contractus el derecho del Estado de Wisconsin, ante la falta de elección expresa de lex arbitri, ésta debía ser la ley belga porque era Bélgica la sede del arbitraje. Por último, otro ejemplo sería el caso suizo, que al igual que el 9(6) de la Ley 60/2003, de 23 de Diciembre, de Arbitraje, con el objetivo de maximizar la eficacia del convenio dispone en el artículo 178/2) de su Ley de Derecho Internacional Privado que: "Quant au fond, elle est valable si elle répond aux conditions que pose soit le droit choisi par les parties, soit le droit régissant l'objet du litige et notamment le droit applicable au contrat principal, soit encore le droit suisse".
} 
expresa de las partes; no existiendo ésta, a la elección implícita de las partes y, finalmente, no existiendo elección expresa o implícita, a la ley que presente una conexión más estrecha y real con el arbitraje.

64. Con el objetivo de facilitar la labor del intérprete en relación con la segunda de las fases, la práctica judicial ha venido a establecer una serie de presunciones que permitirán discernir qué ley es la implícitamente elegida por las partes como lex arbitri.

Pudiendo ser tratadas como un todo o como una parte del todo, será en relación con los convenios de arbitraje que toman la forma de cláusula inserta en un contrato dónde mayores problemas se generarán, especialmente en el supuesto habitual de que las partes hayan expresamente elegido un determinado ordenamiento jurídico para que rija la relación contractual. Así, amparándose en una interpretación sistemática de la cláusula de arbitraje, la Corte de Apelación de Inglaterra y Galés estableció en el caso Sul América que se había de presumir que al elegir expresamente una lex contractus las partes habían pretendido que todas las cláusulas del contrato se rigieran por esa misma ley, incluida la cláusula de arbitraje. Por tanto, conforme a esta doctrina, salvo que existieran indicios que apuntaran en otra dirección, la lex contractus expresamente elegida por las partes se presumía implícitamente elegida como lex arbitri.

Recientemente, la misma Corte de Apelación enmendó esta doctrina en el caso Enka. Considerando que de la lex arbitri va a depender la validez, eficacia o existencia del acuerdo de arbitraje, la Corte concluyó que a efectos de identificar cuál es la lex arbitri era necesario separar la cláusula del resto del contrato. Esto suponía que, dado la estrecha vinculación existente entre la ley de la sede y la ley aplicable al convenio, salvo que existieran motivos extraordinariamente poderosos, la elección de una sede implicaba la elección implícita de su ley como la aplicable al convenio de arbitraje, es decir, se presumiría que la elección de lex locus arbitri conllevará su elección implícita como lex arbitri.

Considerando exorbitante la aplicación del principio de separabilidad defendida por la Corte de Apelación, menos de 6 meses después de su adopción, el Tribunal Supremo enmendó la decisión de la Corte de Apelación y reestableció la presunción de que, a falta de indicios en sentido contrario, la lex contractus elegida por las partes se presumirá implícitamente elegida como ley aplicable a la cláusula de arbitraje.

65. En conclusión, en tanto en cuanto el Tribunal Supremo del Reino Unido no cambie de criterio, a la hora de determinar la lex arbitri de una cláusula de arbitraje inserta en un contrato, la aplicación de la norma de conflicto del common law resultará de la siguiente manera:

A. Cuando existiera una elección expresa de lex arbitri - la cual podrá realizarse en la propia cláusula de arbitraje, en otra cláusula del contrato o derivarse de la combinación de ambas se aplicará la ley elegida con independencia de que sea o no coincidente con la ley aplicable al contrato en que se inserta la cláusula, o con la ley del lugar designado como sede.

B. No existiendo elección expresa de lex arbitri, se atenderá a la ley implícitamente elegida. Así, existiendo una elección de lex contractus en los términos señalados en el artículo 3(1) del Reglamento Roma I, se entenderá que la voluntad implícita de las partes es que esa ley se aplique también a la cláusula de arbitraje. No obstante, no se aplicará esta presunción cuándo:

1. Conforme a la ley aplicable al contrato la cláusula de arbitraje fuera ineficaz, inexistente o inválida.

2. Cuando la ley del lugar elegido por las partes como sede del arbitraje prevea que, a falta de designación expresa de lex arbitri, se aplicará a la cláusula de arbitraje la ley del lugar designado como sede.

C. No existiendo elección expresa o implícita, la ley aplicable al acuerdo de arbitraje será la ley que presente una conexión más estrecha y real con el arbitraje, siendo generalmente ésta la ley del lugar designado como sede del arbitraje. 